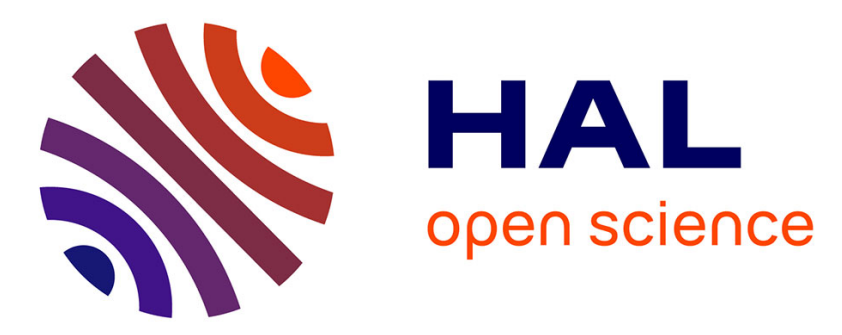

\title{
Rubané et groupe d'Entzheim à Pflugriesheim "Langgarten" et "Buetzel" (Bas-Rhin)
}

\author{
Katia Meunier, Isabelle Sidéra, Rose-Marie Arbogast
}

\section{To cite this version:}

Katia Meunier, Isabelle Sidéra, Rose-Marie Arbogast. Rubané et groupe d'Entzheim à Pflugriesheim "Langgarten" et "Buetzel" (Bas-Rhin). Bulletin de la Société préhistorique française, 2003, 100, pp.267-292. 10.3406/bspf.2003.12837 . halshs-00126342

\section{HAL Id: halshs-00126342 \\ https://shs.hal.science/halshs-00126342}

Submitted on 6 Oct 2020

HAL is a multi-disciplinary open access archive for the deposit and dissemination of scientific research documents, whether they are published or not. The documents may come from teaching and research institutions in France or abroad, or from public or private research centers.
L'archive ouverte pluridisciplinaire HAL, est destinée au dépôt et à la diffusion de documents scientifiques de niveau recherche, publiés ou non, émanant des établissements d'enseignement et de recherche français ou étrangers, des laboratoires publics ou privés. 


\section{Rubané et groupe d'Entzheim à Pfulgriesheim "Langgarten" et} "Buetzel" (Bas-Rhin)

Katia Meunier, Isabelle Sidéra, Rose-Marie Arbogast

\section{Citer ce document / Cite this document :}

Meunier Katia, Sidéra Isabelle, Arbogast Rose-Marie. Rubané et groupe d'Entzheim à Pfulgriesheim "Langgarten" et "Buetzel" (Bas-Rhin). In: Bulletin de la Société préhistorique française, tome 100, n², 2003. pp. 267-292;

doi : https://doi.org/10.3406/bspf.2003.12837

https://www.persee.fr/doc/bspf_0249-7638_2003_num_100_2_12837

Fichier pdf généré le 21/02/2020 


\begin{abstract}
On the site of Pfulgriesheim, one occupation is attributed to the Bandkeramik, another to the Entzheim group. The Bandkeramik settlement is mainly located in the eastern sector. It consists principally of dwelling pits. No buildings have been preserved. The quantity of finds is quite low, but most of the pottery is characteristic of the late Bandkeramik in lower Alsace. The main interest of the site lies in the second occupation, which includes a cluster of pits in the western sector. One pit in particular is exceptional for its assemblage of complete vessels. This closed find associates vessels characteristic of the Entzheim group with typical Michelsberg vessels; it is consequently fundamental for understanding the transition between the Middle and Late Neolithic in lower Alsace. In addition, the specific nature of this deposit raises the question of its functional and symbolic significance.
\end{abstract}

\title{
Résumé
}

Sur le site de Pfulgriesheim, une occupation est attribuée au Rubané, une autre au groupe d'Entzheim. L'occupation rubanée est implantée principalement dans le secteur est. Elle est matérialisée essentiellement par des fosses d'habitat. Les bâtiments ne sont pas conservés. L'ensemble du mobilier est modeste mais la plupart de la céramique est caractéristique du Rubané final de Basse-Alsace. L'intérêt majeur du site porte sur la seconde occupation, représentée par un ensemble de fosses regroupées dans le secteur ouest. Une fosse en particulier est exceptionnelle par son assemblage de vases entiers. Cet ensemble clos associe des vases caractéristiques du groupe d'Entzheim à des vases typiques du Michelsberg ; défait, il est fondamental pour la compréhension de la transition entre le Néolithique moyen et récent en Basse-Alsace. De surcroît, la spécificité de ce dépôt pose la question de sa signification fonctionnelle et symbolique. 
Katia MEUNIER, Isabelle SIDÉRA et Rose-Marie ARBOGAST

\title{
Rubané et groupe d'Entzheim à Pfulgriesheim "Langgarten" et "Buetzel” (Bas-Rhin)
}

\begin{abstract}
Résumé
Sur le site de Pfulgriesheim. une occupation est attribuée au Rubané, une autre au groupe d'Entzheim. L'occupation rubanée est implantée principalement dans le secteur est. Elle est matérialisée essentiellement par des fosses d'habitat. Les bâtiments ne sont pas conservés. L'ensemble du mobilier est modeste mais la plupart de la céramique est caractéristique du Rubané final de Basse-Alsace. L’intérêt majeur du site porte sur la seconde occupation, représentée par un ensemble de fosses regroupées dans le secteur ouest. Une fosse en particulier est exceptionnelle par son assemblage de vases entiers. Cet ensemble clos associe des vases caractéristiques du groupe d'Entzheim à des vases typiques du Michelsberg: de fait, il est fondamental pour la compréhension de la transition entre le Néolithique moyen et récent en Basse-Alsace. De surcroît, la spécificité de ce dépôt pose la question de sa signification fonctionnelle et symbolique.
\end{abstract}

\begin{abstract}
On the site of Pfulgriesheim, one occupation is attributed to the Bandkeramik, another to the Entzheim group. The Bandkeramik settlement is mainly located in the eastern sector. It consists principally of dwelling pits. No buildings have been preserved. The quantity of finds is quite low, but most of the pottery is characteristic of the late Bandkeramik in lower Alsace. The main interest of the site lies in the second occupation, which includes a cluster of pits in the western sector. One pit in particular is exceptional for its assemblage of complete vessels. This closed find associates vessels characteristic of the Entzheim group with typical Michelsberg vessels; it is consequently fundamental for understanding the transition between the Middle and Late Neolithic in lower Alsace. In addition, the specific nature of this deposit raises the question of its functional and symbolic significance.
\end{abstract}

Pfulgriesheim se situe à $10 \mathrm{~km}$ au nord-ouest de Strasbourg (fig. 1). Le site néolithique, établi sur les lieux-dits "Langgarten" et "Buetzel", est implanté sur un flanc de colline surplombant le village de Pfulgriesheim. Celui-ci est traversé par le Leisbach, un affluent de la Souffel. Le substrat géologique est constitué d'une épaisse couche de loess, recouverte d'un lehm d'altération de couleur brune. Le dénivelé du terrain est important en largeur, l'altitude variant de 158 à $161 \mathrm{~m}$ sur une distance de 30 à $37 \mathrm{~m}$. En conséquence, la forte érosion n'a pas toujours permis une bonne conservation des structures.
Le lieu-dit "Buetzel" était déjà connu pour avoir livré des fosses rubanées et protohistoriques lors de la construction de l'oléoduc sud-européen (Wernert, 1963, p. 188 à 189). Un projet de lotissement communal sur 2,3 ha aux lieux-dits "Langgarten" et "Buetzel" a donc donné lieu à un diagnostic qui a mis en évidence deux concentrations de fosses (Flotté et al., 2000). L'opération de fouille s'est axée sur ces deux concentrations, à partir desquelles nous avons décapé une surface de $5000 \mathrm{~m}^{2}$ (Meunier et al., 2001). Hormis cinq fosses datées de La Tène ancienne, le site comporte 24 fosses néolithiques. Celles-ci représentent une 


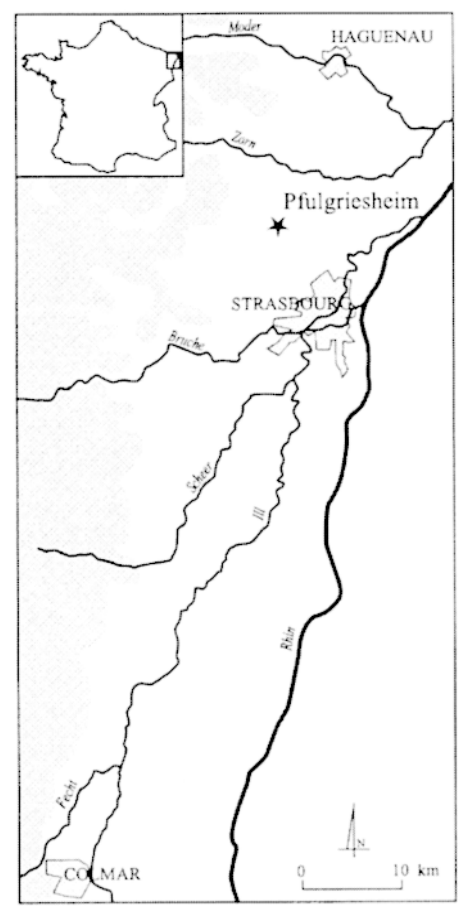

Fig. 1 - Localisation du site.

occupation rubanée et une autre attribuée au Néolithique moyen/récent. C'est sans aucun doute cette dernière qui présente l'intérêt le plus marquant, grâce à la présence d'un dépôt de mobilier (Meunier, 2002).

\section{L'OCCUPATION RUBANÉE}

\section{Les structures}

Treize fosses rubanées sont regroupées dans le secteur est sur une surface d'environ $480 \mathrm{~m}^{2}$ (fig. 2). Celle-ci étant à l'extrémité de l'emprise, les limites de l'occupation sont mal définies. Les fosses ont un plan circulaire ou ovale, parfois irrégulier. Leur profil est en cuvette. On distingue un seul cas de fosse de type "fente" (st. 106b), recoupée par une autre structure. Aucun bâtiment n'a été conservé, de plus l'écartement des fosses ne permet pas de déterminer la présence d'unités d'habitation. Seules les fosses 103 et 104 sont alignées sur un axe nord-ouest/sud-est. Parmi les autres structures, certaines sont disséminées alors que les structures 89, 90 et 109, regroupées, semblent figurer les alvéoles d'une même fosse. Celles-ci s'inscrivent partiellement dans un lambeau de "niveau de sol", défini par une couche de lehm brun foncé. Le matériel est relativement peu abondant et inégalement réparti entre les fosses. Les matériaux de construction, représentés par du torchis rubéfié avec des empreintes de clayonnage, sont attestés en grande quantité exclusivement dans les structures $106(11,5 \mathrm{~kg})$ et $8(6,6 \mathrm{~kg})$. Le secteur ouest est plus pauvre en structures et en matériel mais recèle trois fosses datées du Rubané. Ces fosses sont d'un type différent de celles du secteur est. Deux structures de grande taille $(D=1,20$ à $3 \mathrm{~m}$; $P=1 \mathrm{~m}$ ) en particulier se caractérisent par un fond plat et des parois verticales. Par ailleurs, un fragment de fossé sans mobilier (st. 31) est recoupé par une de ces grandes fosses (st. 66). Il est donc antérieur et date peut-être du Rubané. Enfin l'intrusion d'un tesson rubané dans une fosse du Néolithique moyen/récent (st. 49) montre que les structures rubanées ont pu être perturbées.

\section{La céramique}

\section{Caractères techniques et morphologiques}

Deux catégories de céramique, fine et grossière, ont été reconnues selon des critères morphométriques et techniques : dégraissant, qualité de la finition, type de cuisson.

La céramique grossière est représentée par sept individus : la partie supérieure d'une bouteille à épaulement très marqué, avec 4 anses en boudin placées sous le col (fig. $3, n^{\circ} 1$ ), une coupe basse à fond plat (fig. $5, n^{\circ} 1$, D ouv. $=23 \mathrm{~cm}$ ) et un fragment de coupe $\left(\right.$ fig. $4, \mathrm{n}^{\circ} 1$, $\mathrm{D}$ ouv. $=15 \mathrm{~cm})$. Il faut ajouter quatre fragments de bord, dont l'un est décoré d'impressions digitées. Cette catégorie contient toujours des inclusions en quantité abondante. Il s'agit le plus souvent de sables quartzeux de granulométrie plus ou moins fine (de 0,1 à $1 \mathrm{~mm}$ ). Dans certains tessons, de la coquille grossièrement pilée a été ajoutée à l'argile. Les surfaces sont rugueuses et révèlent des stries très nettes d'égalisation. D'après la couleur de la pâte, noire au cœur, et celle des surfaces variant du beige au noir, la cuisson est à tendance réductrice.

La céramique fine regroupe quelques formes en trois quarts de sphère ou à inflexion. Elle ne contient aucun dégraissant ajouté. La présence de quartz de granulométrie fine $(0,5$ à $1 \mathrm{~mm})$ semble accidentelle. L'examen à la loupe binoculaire a montré des inclusions noires d'oxydes. Les surfaces extérieures, lorsque l'état de conservation le permet, montrent des traces de polissage, alors que certaines surfaces intérieures ont seulement été égalisées avec un outil qui a laissé de fines stries sur le bord interne. Les couleurs de la céramique montrent une cuisson oxydante avec une phase finale réductrice : le cœur est le plus souvent clair, variant du gris clair au beige ou au rouge, et les surfaces sont grises ou noires.

\section{Les décors}

Deux groupes typologiques ont été définis en fonction des techniques de décor et des thèmes. Le premier rassemble la céramique des structures 103 et 104 et le second celle de toutes les autres fosses.

\section{Groupe des structures 103 et 104}

On décompte cinq individus, décorés d'incisions et d'impressions au poinçon.

Trois vases sont décorés d'un thème en chevron. Le plus complet est associé à un petit vase à paroi rentrante (fig. $3, n^{\circ} 5$ ). Le décor est constitué d'une rangée de grosses impressions en amande sous le bord, d'un motif principal en chevron composé d'une ligne incisée bordée de part et d'autre d'impressions du même type que le bord, et d'un motif secondaire formé 

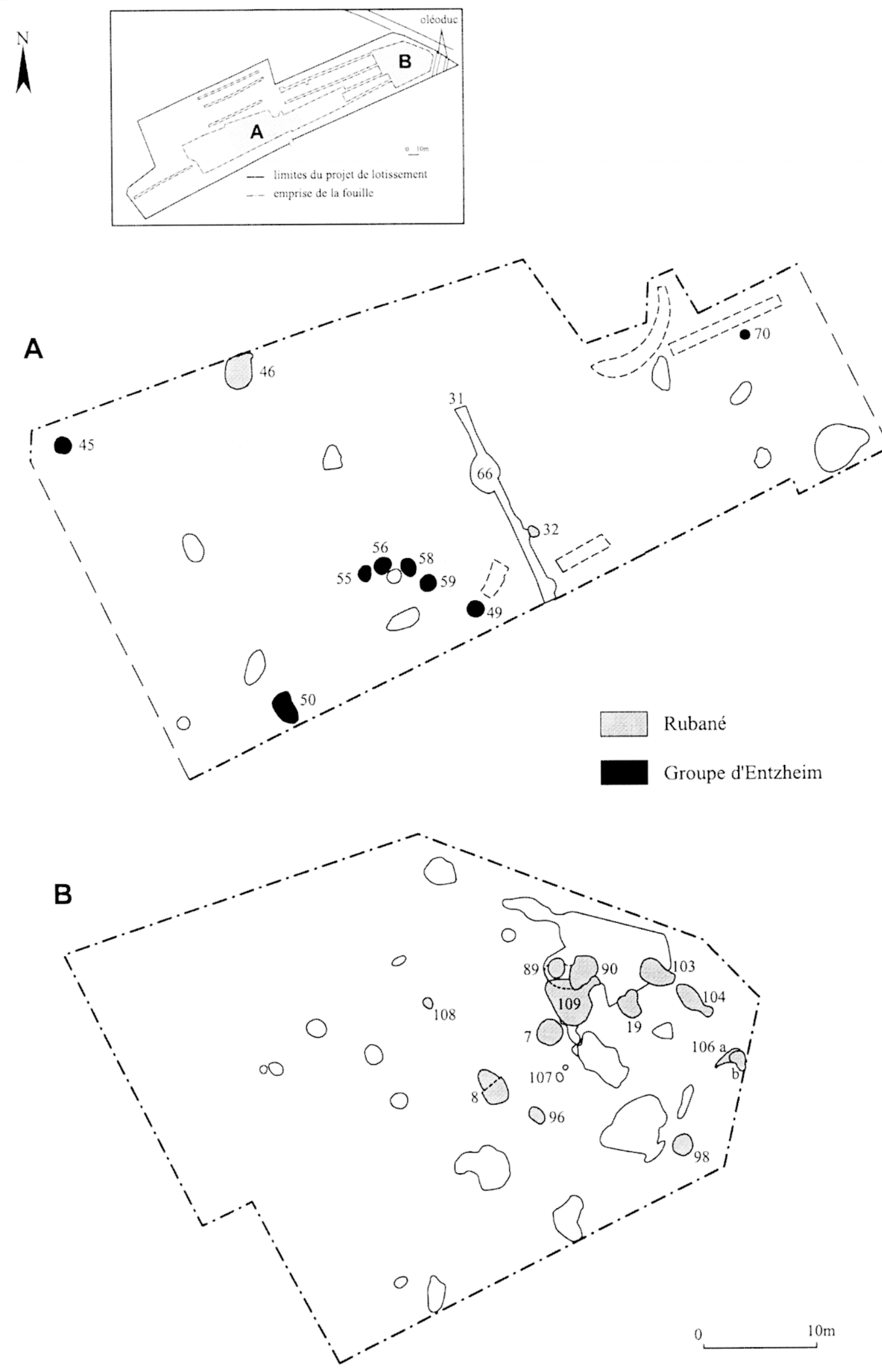
$10 \mathrm{~m}$

Fig. 2 - Plan du site et des parcelles fouillées (mise au net : P. Girard, Inrap). 


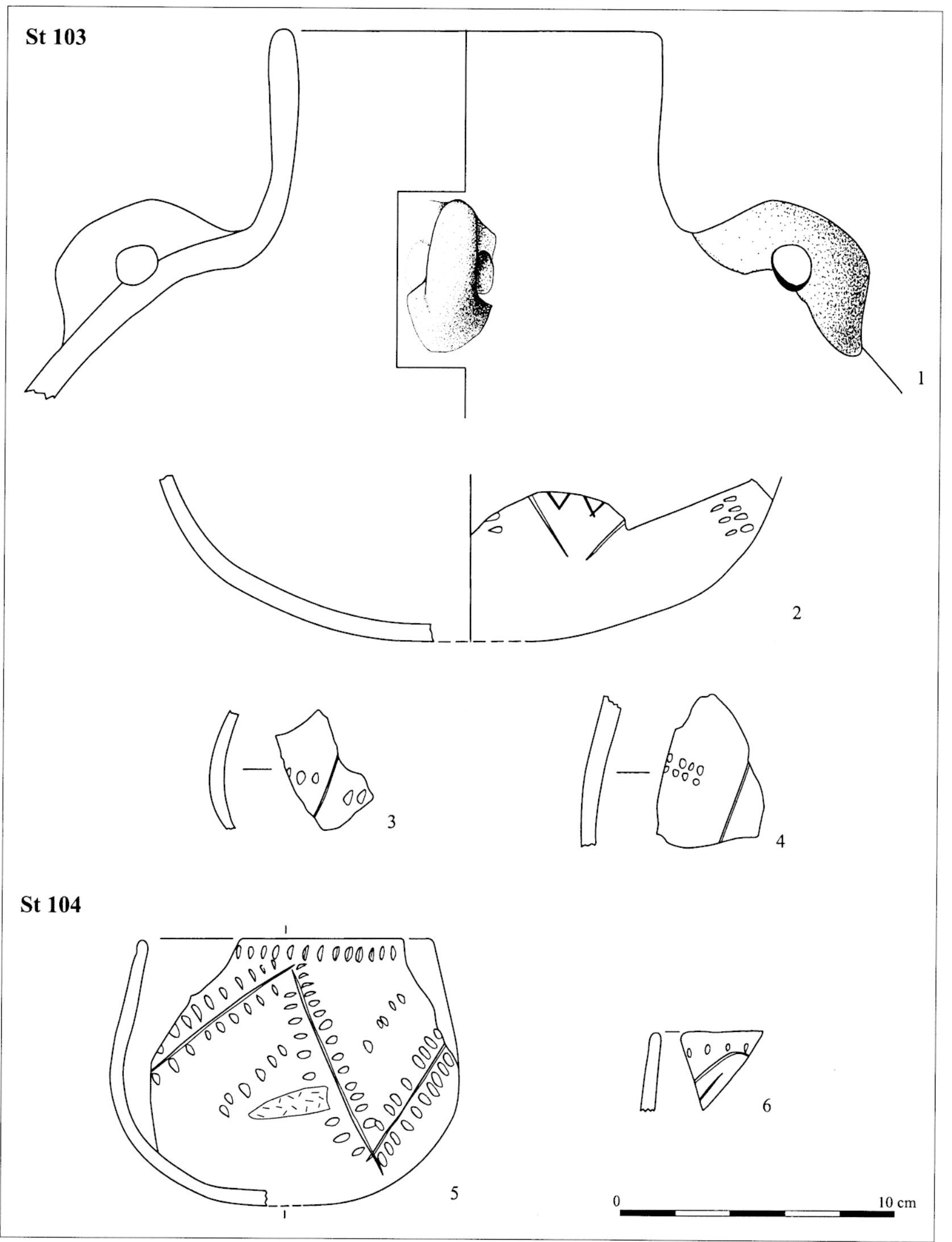

Fig. 3 - Céramique des structures 103 et 104 (dessin : K. Meunier/P. Girard, Inrap). 

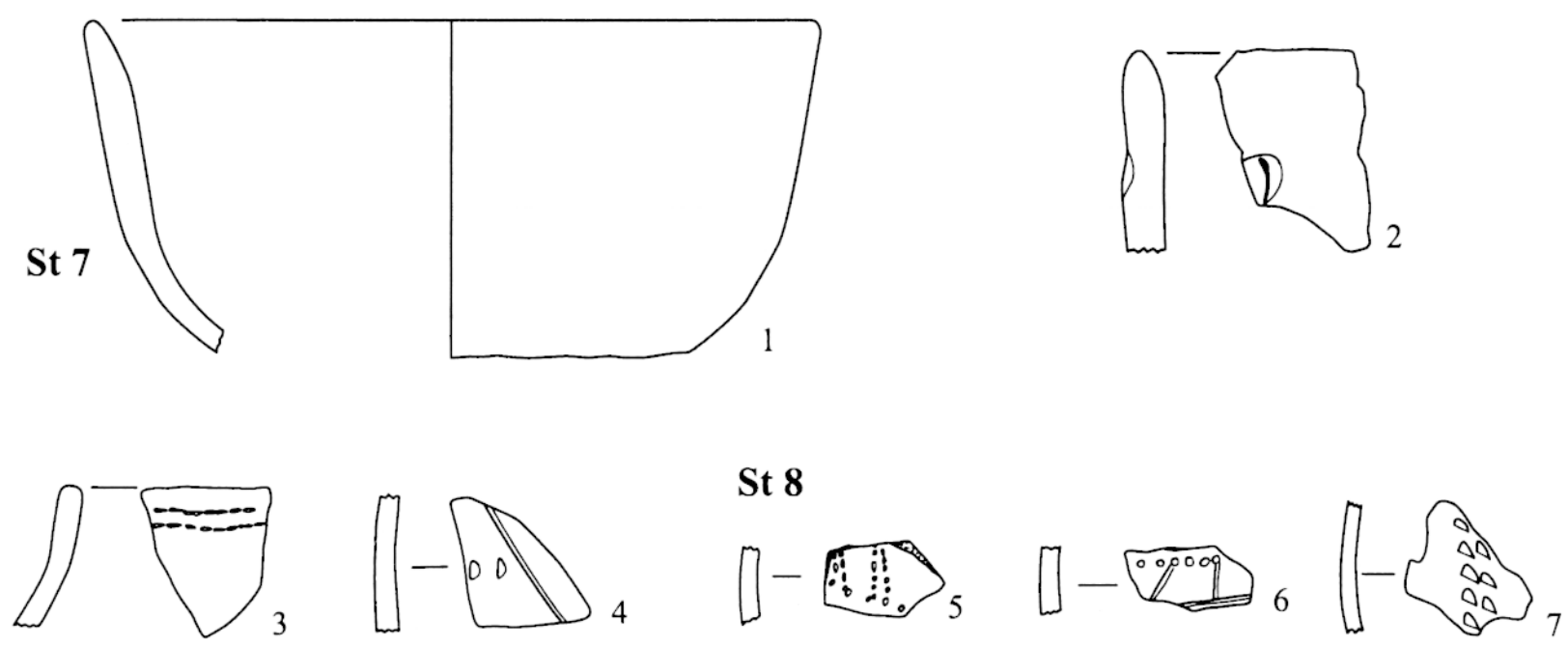

\section{St 89}

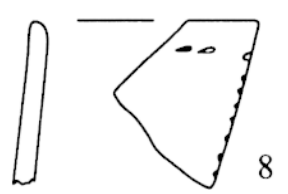<smiles>O=C1CCCCC1</smiles><smiles>c1ccc2ccccc2c1</smiles><smiles>O=C1CCCCC1C1CCCC1</smiles><smiles></smiles>
11
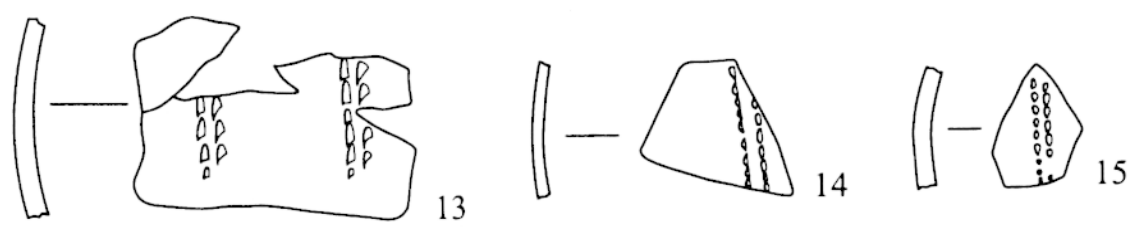

\section{St 90}
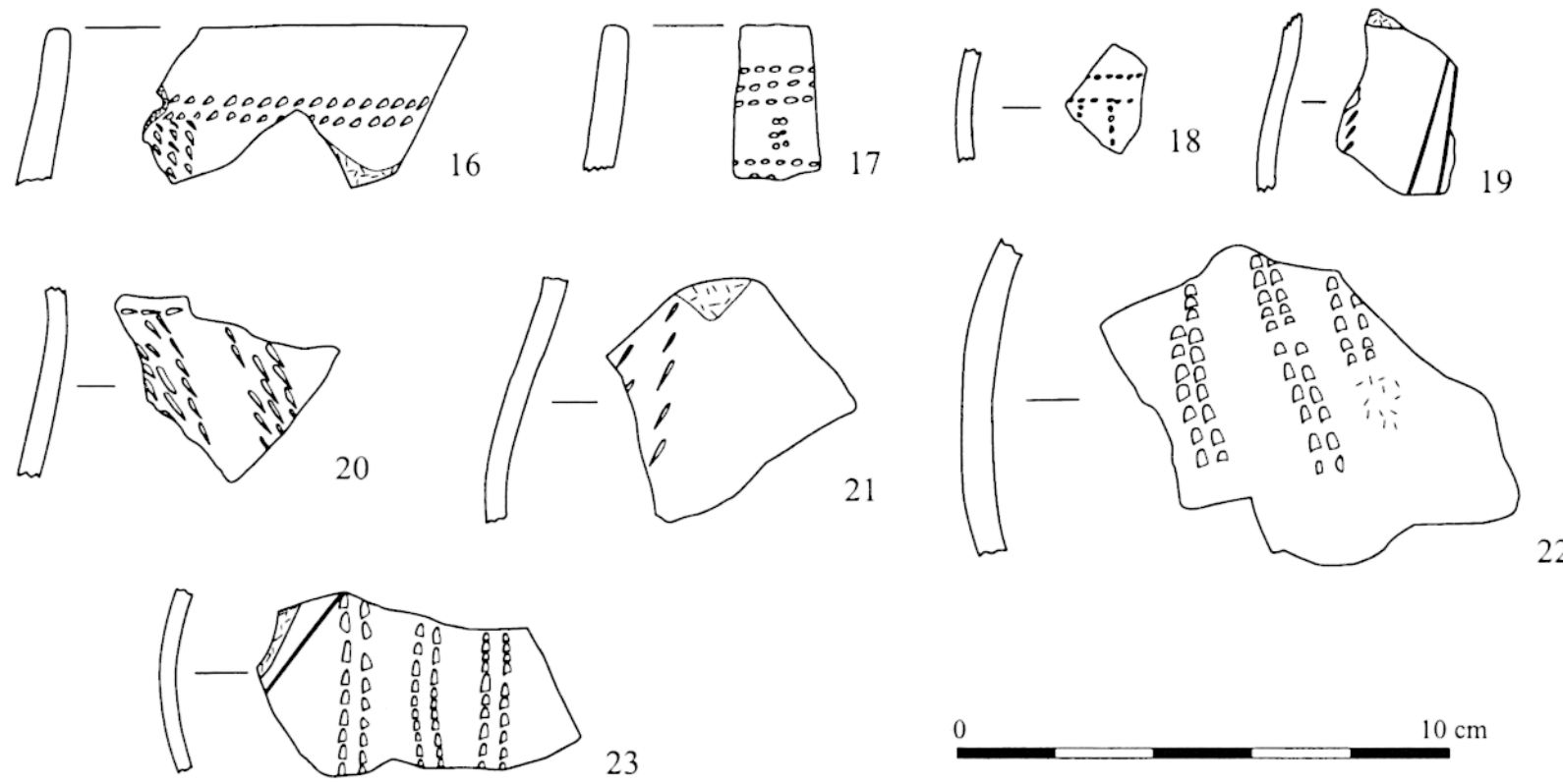

Fig. 4 - Céramique des structures 7. 8.89 et 90 (dessin : K. Meunier/P. Girard. Inrap). 
de segments obliques d'impressions. Parmi les deux autres individus, l'un est représenté par un tesson où seuls sont conservés une ligne incisée et un motif secondaire formé de deux rangées d'impressions au poinçon (fig. $3, n^{\circ} 4$ ). Le second, conservé dans sa partie inférieure, semble plus complexe. Il comprend des petits chevrons ou des triangles encastrés à l'intérieur d'un chevron principal formé d'une ligne incisée. Le décor secondaire est formé de segments obliques imprimés au poinçon (fig. $3, \mathrm{n}^{\circ} 2$ ).

Le décor curviligne est représenté sur deux tessons. Le premier est formé d'une rangée d'impressions ovalaires sous le bord et d'un ruban incisé (fig. $3, n^{\circ} 6$ ). Le second est probablement composé d'une seule ligne incisée complétée de motifs secondaires horizontaux d'impressions en amande (fig. $3, n^{\circ} 3$ ).

\section{Groupe des structures 7, 8, 89, 90, 98, 106 et 109}

Le corpus est constitué de 34 individus décorés. Parmi les techniques de décor, la mieux représentée est celle de l'impression au poinçon (23 individus). On distingue plusieurs techniques d'utilisation du poinçon : les impressions "en virgule" et les petites impressions circulaires ou ovales prédominent et ont été utilisées de façon équivalente, alors que les impressions plus grosses, ovales ou en demi-lune, sont attestées sur quatre individus. Le peigne à 2 dents est attesté sur 8 individus. Il a été utilisé en impression séparée dans un seul cas (fig. $4, \mathrm{n}^{\circ} 12$ ) et en impression pivotante sur sept vases (fig. $4, n^{\text {os }} 22$ et 23 ; fig. 5 , n ${ }^{\text {os }} 13$ et 14 ). L'incision est en général associée à des impressions réalisées au poinçon ou au peigne.

Le décor sous le bord a été identifié sur dix fragments de bords et un tesson :

- une rangée d'impressions rondes ou "en virgule" réalisées au poinçon (fig. $3, \mathrm{n}^{\circ} 6$; fig. $4, \mathrm{n}^{\circ} 9$ et fig. $5, \mathrm{n}^{\circ} 2$ );

- deux rangées d'impressions au poinçon (fig. $4, n^{\text {os }} 3$ et 16 );

- trois rangées d'impressions "en virgule" au poinçon (fig. $5, n^{\circ} 9$ );

- cinq rangées d'impressions au poinçon entrecoupées de segments verticaux, ou décor orthogonal (fig. 4, $\left.\mathrm{n}^{\circ} 17\right)$;

- un décor orthogonal non complet réalisé au poinçon (fig. $4, n^{\circ} 5$ );

- une bande d'impressions au peigne à 2 dents en mode pivotant (fig. $5, \mathrm{n}^{\circ} 14$ );

- deux bandes minimum d'impressions au peigne à 2 dents en mode pivotant (fig. $5, \mathrm{n}^{\circ} 13$ ).

On peut distinguer deux grands types de décor principal représentés sur 13 individus, très fragmentés : le décor en chevron et le décor de bandes verticales, celles-ci pouvant appartenir à un décor en $\mathrm{T}$ ou à un décor orthogonal, puisque seule la partie supérieure du vase est conservée. Les décors suivants ont été reconnus :

- décor en chevron poinçonné (fig. $\left.5, \mathrm{n}^{\circ} 12\right)$ ou incisé de une, deux, ou trois lignes (fig. $5, n^{\circ} 2$ ). Sur deux thèmes en chevron incisé, des bandes verticales imprimées au poinçon ou au peigne à deux dents en impression pivotante complètent le motif principal (fig. $4, n^{\circ} 23$; fig. $5, n^{\circ} 4$ );

- décor de bandes verticales. Les techniques utilisées pour ce thème sont l'impression "en virgule" (fig. 4 , $n^{\circ} 20$; fig. $5, n^{\circ} 9$ ) et le peigne à deux dents utilisé en impression pivotante (fig. $5, \mathrm{n}^{\circ} 14$ ). Dans le cas de cette dernière technique, les bandes, peu espacées, sont en alternance avec trois lignes verticales incisées et forment un décor couvrant. Pour ce type de décor, seul le haut de la panse étant conservé, il s'agit peut-être d'un décor orthogonal.

\section{Interprétation chronologique}

Dans le groupe typologique représenté dans les structures 103 et 104, les rares individus céramiques dont nous disposons ne sont pas assez représentatifs pour pouvoir proposer une attribution chronologique précise. Le thème en chevron associant incision et impressions en amandes de la structure 104 est en effet peu représenté dans le Rubané. Dans le Rubané alsacien, il est comparable à un seul vase de Rosheim "Sainte-Odile" attribué au Rubané récent (Jeunesse, 1992, pl. 1, no 3 ). Il existe aussi en Moselle dès le Rubané moyen (Dohrn-Ihmig, 1974, fig. 4, $\mathrm{n}^{\circ} 4$ ). Quant au décor de chevrons complexes du vase de la structure 103, il n'a pas d'élément de comparaison dans la région. Enfin, les rares fragments de décor curvilinéaire, caractéristiques du Rubané moyen alsacien, peuvent perdurer jusqu'à l'étape récente du Rubané. En conséquence, on ne peut attribuer ces décors à une fourchette plus précise que le Rubané moyen-récent.

À l'intérieur du second groupe, les structures 7, 98 et 106 n'ont pas livré suffisamment d'éléments céramiques significatifs et peuvent appartenir aussi bien au Rubané récent qu'au Rubané final. En revanche, la céramique des structures 8,89 et 90 ainsi que les tessons issus des fosses 49 et 52 du secteur ouest possèdent des caractères affirmés du Rubané final du BasRhin, selon les critères de P. Lefranc (Lefranc et al., 1998). Il s'agit d'une bonne représentation des petites impressions au poinçon et des impressions au peigne à 2 dents et de la présence de décors de type "Dachstein" : décor sous le bord poinçonné orthogonal et motif principal de bandes imprimées verticales appartenant probablement à un décor orthogonal. Malgré la modestie de l'échantillon, on remarque que le peigne à deux dents utilisé en impression pivotante est surreprésenté par rapport à d'autres séries du Rubané final du Bas-Rhin, pourtant bien plus importantes. En effet, si le peigne à deux dents domine dans certains sites, en particulier à Westhouse "Ziegelhof", où il est représenté jusqu'à $58 \%$ dans l'une des fosses, l'impression pivotante y est absente (Lefranc et al., 1998, p. 12). En outre, à Rosheim "Sainte-Odile", l'impression pivotante du peigne à deux dents est attestée mais demeure anecdotique par rapport à l'ensemble des impressions au poinçon (Jeunesse et Lefranc, 1999). Enfin, dans l'ensemble des structures, certaines caractéristiques du Rubané récent persistent, comme 
les impressions "en virgule" au poinçon et le décor en chevron.

\section{Le mobilier lithique}

Le mobilier lithique issu de l’occupation rubanée est peu abondant. Il est représenté par un éclat, un fragment de lame en silex retouchée et une boucharde fabriquée dans une roche verte de provenance probablement vosgienne (st. 7). Le reste du matériel concerne des outils de broyage et de polissage représentés par un petit fragment de plan de broyage provenant de la structure $106 \mathrm{~b}$ ainsi que trois pièces fracturées (fig. 6).
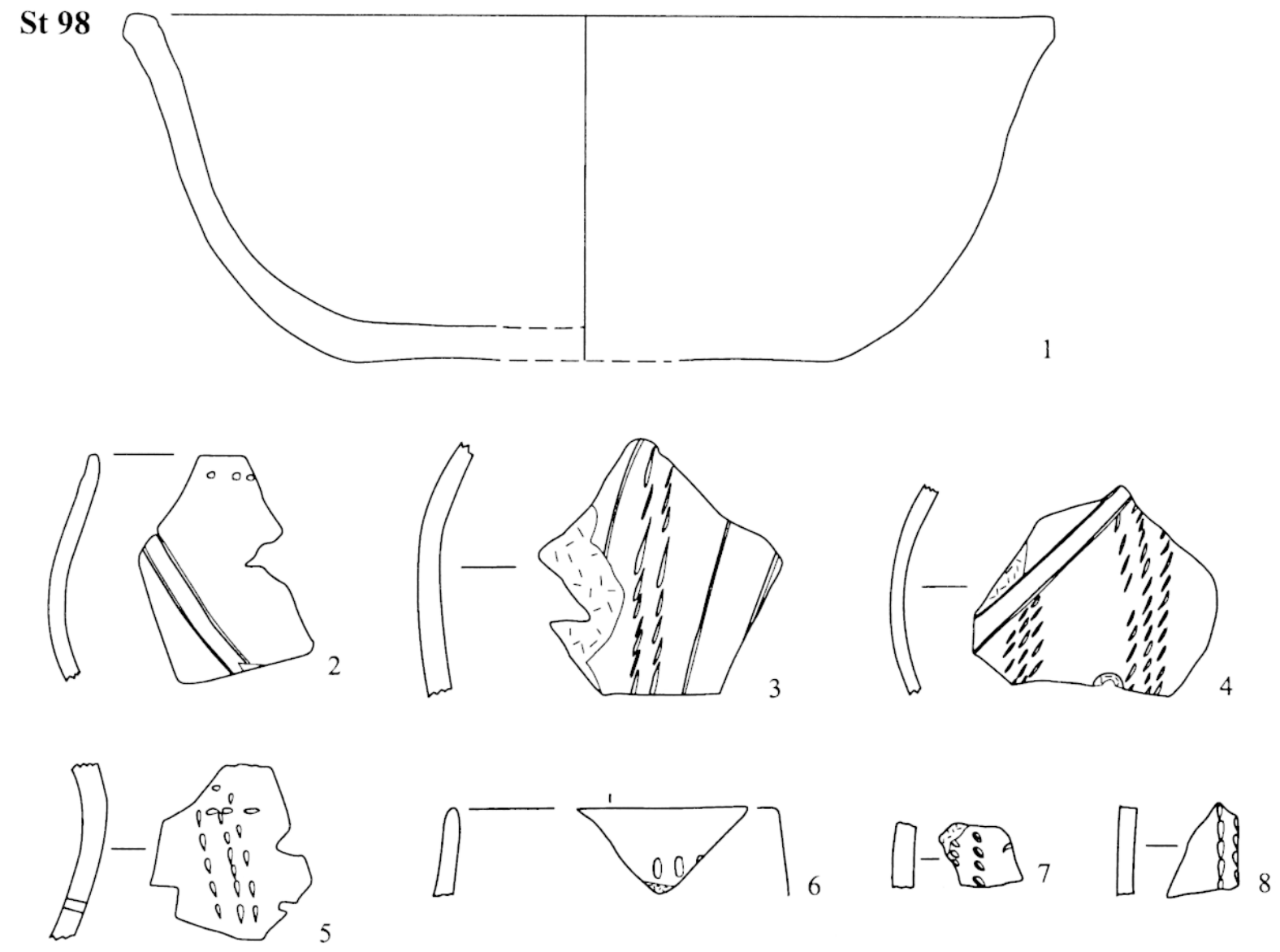

\section{St 106}
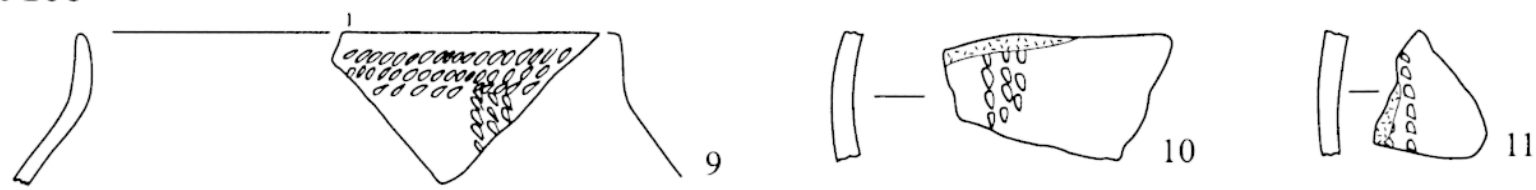

St 46

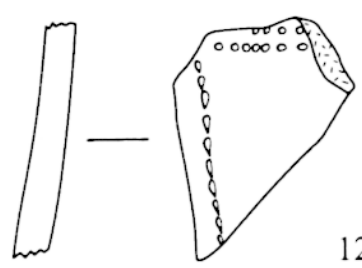

St 49

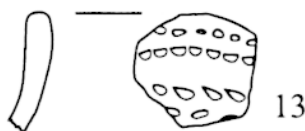

St 52

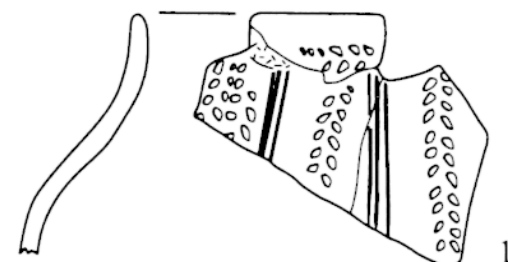

Fig. 5 - Céramique des structures 98, 106, 46, 49 et 52 (dessin : K. Meunier/P. Girard, Inrap). 


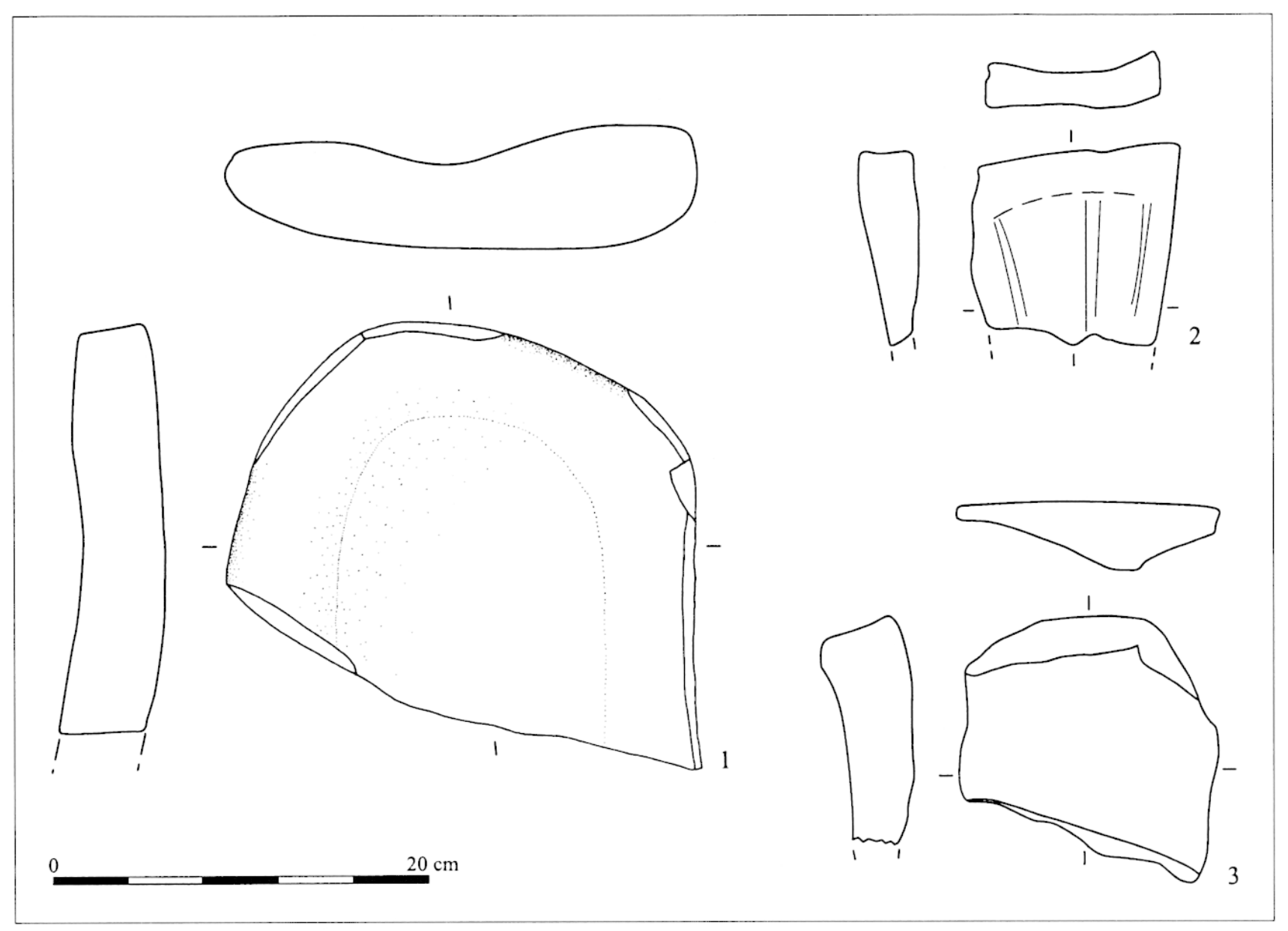

Fig. 6 - Matériel lithique. $\mathrm{N}^{\circ} 1:$ structure $107 ; \mathrm{n}^{\circ} 2:$ structure $96 ; \mathbf{n}^{\circ} 3:$ structure 98 (dessin : K. Meunier/P. Girard, Inrap).

Une meule provenant de la structure 98 , brisée en largeur, a été fabriquée dans un granit gris (fig. $6, \mathrm{n}^{\circ} 3$ ). Elle est de forme oblongue et de section triangulaire. La surface active est concave longitudinalement. L'extrémité conservée est très épaisse et légèrement convexe en largeur. Le dos a été façonné et la surface active montre un piquetage assez grossier.

Un polissoir en grès jaune (st. 96), relativement fin, présente des traces de chauffe superficielles (fig. 6 , $n^{\circ} 2$ ). Brisé en largeur, il est de forme et de section rectangulaires avec un dos plat et des bords droits. La surface active est fortement concave $(0,8 \mathrm{~cm})$, marquée par de légères rainures obliques et longitudinales. Elle ne montre cependant aucune trace de poli.

Enfin, une meule provient d'une légère cuvette de $40 \mathrm{~cm}$ de diamètre, stérile (st. 107). C'est uniquement par sa présence dans le secteur rubané qu'on peut proposer de l'attribuer au Rubané. La meule, façonnée dans un grès gris-rose, a été fracturée dans sa largeur (fig. $6, n^{\circ}$ 1). De forme probablement oblongue et de section ovoïde, elle présente une surface active ovale fortement concave $(1,6 \mathrm{~cm})$ de $18 \mathrm{~cm}$ de large. Le dos, convexe et régulier, présente des traces de piquetage et les bords ont été aménagés par des enlèvements. Malheureusement la lisibilité de la surface active se heurte à l'abondance de concrétions.

\section{L'industrie osseuse}

La fouille du site a mis au jour deux pièces dans une même fosse (st. 7). Nous en livrerons ici une description et nous les rapprocherons des types existants. Grâce à l'étude de plusieurs séries rubanées d'importance, Cuiry-lès-Chaudardes (Sidéra, 1989) et Vaihingen (Stuttgart, Allemagne) (Krause et al., 2000), auxquelles s'ajoutent les petites séries de Wettolsheim (Sidéra, 2000a) et d'Ensisheim (Ehretsman, 1993; Sidéra, 2000a), la technologie et les utilisations des industries osseuses des habitats du Rubané deviennent de mieux en mieux documentées. Cela permet de replacer les pièces dans un contexte chronoculturel précis.

Structure 7 , objet 1 (fig. $7, n^{\circ} 1$ ) : outil perforant entier fabriqué à partir d'un métatarse de cervidé (cerf?) scié en deux (longueur $=169 \mathrm{~mm}$ ). Le segment de l'articulation distale conservé pour former une poignée n'est pas épiphysé. La pièce ne présente pas un état de conservation excellent mais certaines traces de fabrication sont encore présentes. Les traces de sciage bilatérales sont claires et occupent la base de la pièce. Elles sont recoupées par une abrasion qui a traité chacun des bords de découpe de la face inférieure et chaque profil, peut-être pour régulariser le fût. Cette abrasion n'a pas beaucoup changé le volume 
de la section qui garde sa forme de "croissant tronqué" typique de la technique de sciage en deux. La face supérieure est pareillement couverte, de la pointe jusqu'au dessus de l'épiphyse, de stries d'abrasion centrées qui ont très peu d'incidence sur le volume. L'apex est piquant et couvert d'un poli local brillant avec des stries annulaires (jusqu'à $8 \mathrm{~mm}$ ). L'instrument a perforé et passé des matières souples résistantes, probablement de la peau.

Ce type de pièces longues réalisées sur ossement de cervidé sont généralement appelées "poignards" à tort car ce ne sont pas des armes mais des outils. Elles se rencontrent à la fin du Rubané, plus particulièrement dans le Rubané final. C. Jeunesse signale un poinçon de ce standard dans une tombe d'Ensisheim (Jeunesse, 1997, p. 132).

Structure 7 , objet 2 (fig. $7, \mathrm{n}^{\circ} 2$ ) : segment d'une côte de gros animal (cerf ou bœuf) fendue en deux pour en extraire une lame d'os corticale souple et mince. L'état de conservation de l'objet est médiocre. Brisé en largeur et en longueur et ainsi privé des attributs fonctionnels qui permettraient de le classer dans une catégorie spécifique, l'objet constitué est difficilement identifiable. L'une des deux extrémités est préservée. La tranche a été abrasée pour former un arc de cercle. À ce niveau, la face inférieure est raclée, voire abrasée.

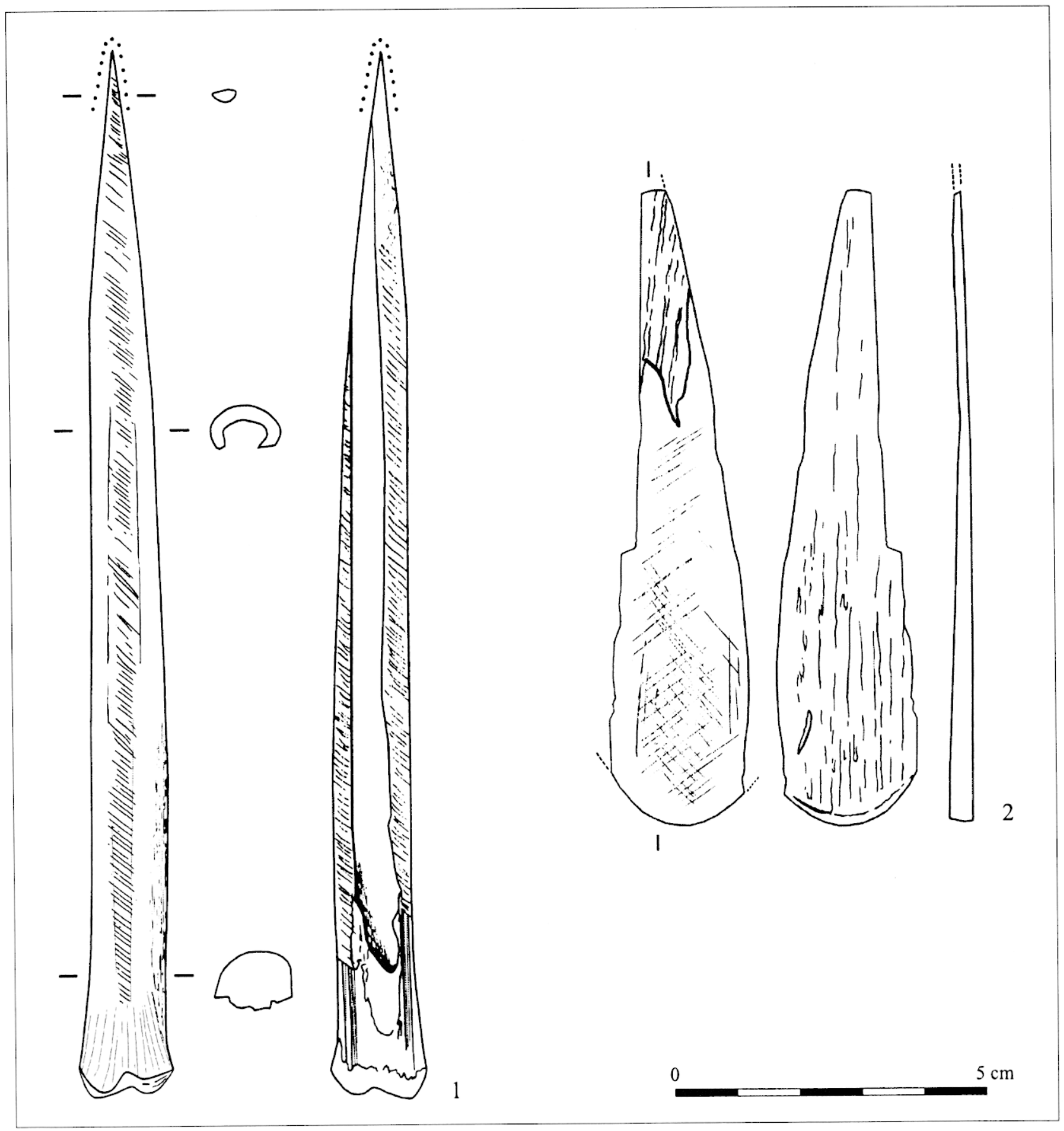

Fig. 7 - Industrie osseuse de la structure 7. $\mathrm{N}^{\circ} 1:$ outil perforant scié en deux $; \mathrm{n}^{\circ} 2:$ fragment proximal d'outil indéterminé, grattoir probable (dessin : I. Sidéra). 
Ce sont vraisemblablement les restes d'une opération d'égalisation de l'os spongieux pour tenir l'instrument avec confort. Aussi, l'extrémité conservée n'estelle pas la partie active mais plutôt la terminaison d'un outil. Un poli qui correspond probablement à la préhension de l'instrument se développe d'ailleurs sur les arêtes et l'os spongieux sommital. Au vu des outils que l'on connaît du Rubané alsacien, l'on verrait dans ce fragment de pièce l'extrémité proximale d'un large grattoir brisé.

Ce type d'outil est, avec les outils perforants, parmi les plus courants de la trousse à outils rubanée (Sidéra, 1989). Le site d'habitat d'Ensisheim en a livré plusieurs (Sidéra, 2000a, fig. 6, $\mathrm{n}^{\circ} 117$ ). Les deux outils de Pfulgriesheim sont entièrement conformes aux trouvailles les plus communes des fosses d'habitat du Rubané. La longueur du poinçon et l'espèce qui a été choisie pour le fabriquer témoignerait cependant davantage des savoir-faire de l'étape finale du Rubané.

\section{Les restes de faune}

Les vestiges osseux d'animaux associés aux structures rubanées du site de Pfulgriesheim "Langgarten et Buetzel" représentent un lot de faune assez modeste, d'une centaine de restes déterminés (tabl. 1, annexe 1) et d'un état de conservation qui témoigne de conditions de gisement assez favorables. Les surfaces osseuses sont fraîches et les effets de l'acidité des sédiments lœssiques, peu prononcés. Dans la plupart des cas l'érosion des surfaces, sous forme de cupules ou de vermiculures, est discrète, de sorte que des biais d'origine taphonomique semblent relativement peu marqués. La principale limite de l'étude de ce mobilier réside dans la modestie des lots d'ossements associés à chaque structure. En fait seul l'ensemble issu de la structure 8 comptabilise plus d'une centaine de pièces alors que les autres échantillons n'en comptent au mieux que quelques dizaines. Cette dispersion des vestiges entre différentes structures peu riches souligne le caractère résiduel de la plupart des échantillons. Les restes associés aux structures datées du Rubané présentent les caractères classiques de rejets culinaires. Ils se présentent sous forme d'os dissociés et fragmentés et dans certains cas partiellement brûlés. Cet état autant que leur localisation dans des structures réutilisées comme dépotoirs sont autant d'indices qui permettent, en première approche, de leur conférer un statut détritique.

La composition des lots d'ossements livrés par les différentes structures est marquée par l'importance de la représentation des restes d'animaux domestiques.

\begin{tabular}{|c|c|c|c|c|c|c|c|c|c|}
\hline & \multicolumn{6}{|c|}{ Rubané final } & \multicolumn{2}{|c|}{ Rubané moyen } & \multirow[b]{2}{*}{ TOTAL } \\
\hline NR & St. 7 & St. 8 & St. 89 & St. 90 & St. 96 & St. 98 & St. 103 & St. 104 & \\
\hline $\begin{array}{l}\text { Bœuf } \\
\text { Porc } \\
\text { Caprinés } \\
\text { Chèvre } \\
\text { Mouton } \\
\text { Chien } \\
\end{array}$ & $\begin{array}{l}1 \\
1 \\
1\end{array}$ & $\begin{array}{r}12 \\
21 \\
21 \\
1 \\
1 \\
3 \\
\end{array}$ & $\begin{array}{l}5 \\
3 \\
5\end{array}$ & $\begin{array}{l}1 \\
1 \\
2\end{array}$ & 2 & 1 & & 11 & $\begin{array}{r}19 \\
39 \\
29 \\
2 \\
\\
3\end{array}$ \\
\hline Total domestiques & 3 & 59 & 13 & 4 & 2 & 1 & & 11 & 93 \\
\hline $\begin{array}{l}\text { Aurochs } \\
\text { Cerf } \\
\text { Sanglier } \\
\text { Chevreuil }\end{array}$ & & $\begin{array}{l}1 \\
5 \\
\end{array}$ & & & 2 & & 1 & & $\begin{array}{l}1 \\
1 \\
2 \\
5\end{array}$ \\
\hline Total sauvages & & 6 & & & 2 & & 1 & & 9 \\
\hline $\begin{array}{l}\text { Total déterminés } \\
\text { Petits ruminants } \\
\text { Suidés } \\
\text { Indéterminés }\end{array}$ & 1 & $\begin{array}{r}2 \\
2 \\
41 \\
\end{array}$ & 14 & 5 & 1 & 5 & & 10 & $\begin{array}{r}102 \\
2 \\
3 \\
76 \\
\end{array}$ \\
\hline TOTAL & 4 & 110 & 27 & 9 & 5 & 6 & 1 & 21 & 183 \\
\hline & \multicolumn{6}{|c|}{ Rubané final } & \multicolumn{2}{|c|}{ Rubané moyen } & \\
\hline PR (g.) & St. 7 & St. 8 & St. 89 & St. 90 & St. 96 & St. 98 & St. 103 & St. 104 & TOTAL \\
\hline $\begin{array}{l}\text { Bœuf } \\
\text { Porc } \\
\text { Caprinés } \\
\text { Chèvre } \\
\text { Chien } \\
\end{array}$ & $\begin{array}{r}46 \\
2 \\
3\end{array}$ & $\begin{array}{r}590 \\
175 \\
75 \\
29 \\
7 \\
\end{array}$ & $\begin{array}{r}161 \\
27 \\
17\end{array}$ & $\begin{array}{r}24 \\
1 \\
4\end{array}$ & 13 & 30 & & 70 & $\begin{array}{r}821 \\
288 \\
99 \\
59 \\
7\end{array}$ \\
\hline Total domestiques & 51 & 876 & 205 & 29 & 13 & 30 & & 70 & 1274 \\
\hline $\begin{array}{l}\text { Aurochs } \\
\text { Cerf } \\
\text { Sanglier } \\
\text { Chevreuil }\end{array}$ & & $\begin{array}{l}35 \\
53 \\
\end{array}$ & & & 12 & & 300 & & $\begin{array}{r}300 \\
35 \\
12 \\
53 \\
\end{array}$ \\
\hline Total sauvages & & 88 & & & 12 & & 300 & & 400 \\
\hline $\begin{array}{l}\text { Petits ruminants } \\
\text { Suidés } \\
\text { Indéterminés }\end{array}$ & 6 & $\begin{array}{l}10 \\
14 \\
90 \\
\end{array}$ & 69 & 10 & 6 & 20 & & 13 & $\begin{array}{r}\mathbf{1 6 7 4} \\
10 \\
20 \\
208 \\
\end{array}$ \\
\hline TOTAL & 57 & 1078 & 274 & 39 & 31 & 50 & 300 & 83 & 1912 \\
\hline
\end{tabular}

Tabl. 1 - Décompte par espèce et par structure des restes de faune datés du Rubané (NR : nombre de restes, PR : poids des restes). 
Les restes les plus nombreux sont attribués au porc. Les petits ruminants sont également bien représentés alors que la place du bœuf. relégué en troisième rang. semble très modeste. Cette image de l'importance relative des différents animaux domestiques est peu conforme à celle que restituent les échantillons d'autres sites rubanés du nord de l'Alsace généralement marqués par la prépondérance de l'élevage bovin et le développement de celui du porc comme principale ressource complémentaire. Il est bien délicat d'apprécier dans quelle mesure cette originalité procède de modalités d'élevage particulières plutôt que d'un défaut de représentativité statistique. Il faut aussi souligner que sur la base du poids des restes se retrouve une configuration inversée, marquée par la prépondérance du bœuf, le rôle complémentaire de l'élevage du porc et la très faible importance des petits ruminants, soit une répartition plus conforme à celle enregistrée par la plupart des faunes contemporaines (Arbogast, 1994). Les ossements d'animaux sauvages se rapportent à l'aurochs, au cerf, au chevreuil et au sanglier, soit aux principaux ongulés qui composent les tableaux de chasse des sites du Néolithique ancien de la plaine d'Alsace. Leur représentation assez modeste signale une chasse assez peu développée mais d’importance comparable à celle qu'enregistrent les faunes contemporaines de la région.

\section{Bilan de l'occupation rubanée}

À l'exception des structures 103 et 104 , le petit ensemble rubané de Pfulgriesheim s"intègre dans le cadre du Rubané final de Basse-Alsace. Les traits caractéristiques sont aussi bien représentés dans la céramique, avec le décor de type "Dachstein" et le peigne à deux dents, que dans l'outillage osseux et l'éventail des espèces animales domestiques et chassées. La fréquence relativement élevée de l'impression pivotante au peigne à deux dents semble spécifique au site. Cet élément pourrait relever de l'aspect tardif de l'occupation par rapport au Rubané final de la région, mais la faiblesse du corpus engage à modérer cette interprétation.

\section{L'OCCUPATION DU GROUPE D'ENTZHEIM}

\section{Les structures}

Huit fosses datées du Néolithique moyen/récent sont concentrées dans le secteur ouest (fig. 2). Seule la structure 50 est de forme oblongue et irrégulière. Les autres fosses. de forme subcylindrique, figurent probablement des fonds de silo. Leur profondeur n excède pas $40 \mathrm{~cm}$. Seule la structure 56 , la plus profonde $(70 \mathrm{~cm})$ représente l'unique forme complète "en silo" : parois rentrantes, diamètre de $1,20 \mathrm{~m}$ à l'ouverture et de $1.46 \mathrm{~m}$ à la base. Le mobilier est très inégalement réparti selon les structures. Dans la plupart des fosses, on compte un seul ou deux vases archéologiquement complets. Parallèlement, les restes osseux et l'industrie lithique sont peu abondants. Deux structures font exception par la qualité de leur matériel : les structures 70 et 58 . La structure 70 se caractérise par une relative abondance de restes de faune $(3200 \mathrm{~g}$ contre 320 à $660 \mathrm{~g}$ dans les autres fosses). regroupés en plusieurs petits amas. Un fragment de disque en terre cuite est disposé verticalement contre la paroi de la fosse. Quant à la structure 58, elle contient une petite série de vases entiers.

\section{Le dépôt de la structure 58 : description}

La morphologie de la structure 58 est semblable à celle des autres fosses cylindriques du site. Le remplissage est constitué de limon brun homogène avec une perturbation dans la moitié sud qui se manifeste par un mélange de limon et de losss (fig. 9). La fosse contient six vases entiers : un vase ouvert en demi-sphère, un vase tulipiforme, deux bouteilles dont une décorée et deux disques en terre cuite. Sept vases se présentent sous forme de fragments parmi lesquels ont pu être restitués trois vases tulipiformes, une cruche et un puisoir.

Les vases sont disposés selon une organisation concentrique, la majeure partie étant regroupée dans la moitié nord de la fosse (fig. 8). Aucun vase ne repose directement sur le fond, mais sur une fine couche de limon brun, variant de 2 à $10 \mathrm{~cm}$. Les vases $\mathrm{n}^{0 \prime} 1$, 2,3 et 4 , les plus complets, sont placés le long de la paroi nord : le grand vase ouvert $n^{\circ} 1$ a été légèrement écrasé par le poids du sédiment, le vase $n^{\circ} 2$ et la bouteille $n^{\circ} 4$, probablement instables du fait de leur base ovoïde, sont couchés sur leur panse et la bouteille décorée $n^{\circ} 3$ est posée selon un axe subvertical. Un fragment de panse $\left(n^{\circ} 7\right)$ chevauche les vases $n^{\circ 5} 3$ et 4 (fig. 9). Un fond $\left(n^{\circ} 8\right)$ s'intercale entre les vases $n^{\text {os }} 2$ et 3 (fig. 9). Un disque en terre cuite $\left(n^{\circ} 5\right)$, presque vertical, repose en partie à l'intérieur du vase $\mathrm{n}^{\circ} 2$ et est appuyé contre la bouteille $n^{\circ} 3$ (fig. 10). L'espace entre les vases $n^{\circ \infty} 2$ et 4 est comblé par un amas de tessons provenant de plusieurs vases et quelques restes de faune (fig. 9). Le second disque en terre cuite $\left(n^{\circ} 6\right)$ est disposé contre la paroi sud de la fosse, en position subverticale. déformé par le poids du comblement (fig. 8). Enfin, l'ensemble du remplissage de la fosse contient d'autres tessons, des restes osseux, ainsi que deux pendeloques sur canine. L'une de ces deux pendeloques est située sur l'épaulement du vase ${ }^{\circ} 4$, mais il n'existe aucun indice pour discerner le caractère intentionnel ou accidentel de cette disposition. Aussi est-il délicat de préciser la nature de l'association de ces pendeloques au dépôt de vases.

La présence de vases entiers, leur organisation et le positionnement vertical des disques en terre cuite suggère un dépôt intentionnel. Par ailleurs, la composition de ce dépôt est frappante par la diversité des formes et les caractéristiques dimensionnelles des vases. La spécificité de ce dépôt apparaît plus clairement dans l'étude typologique des vases qui suit.

\section{La céramique du dépôt}

\section{Caractères techniques}

L'épaisseur des vases est toujours comprise entre 5 et $8 \mathrm{~mm}$, exceptés les disques en terre cuite dont 

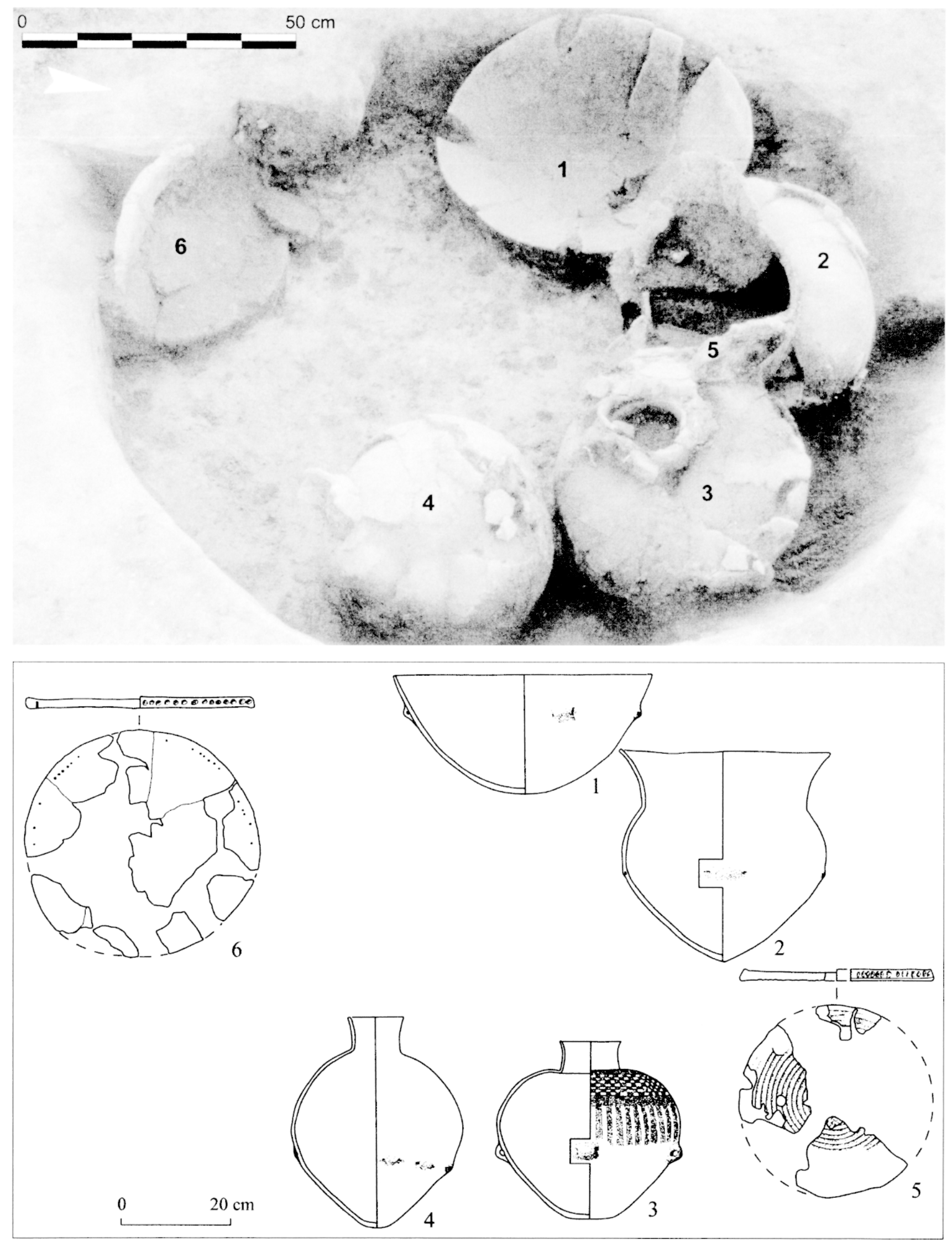

Fig. 8 - Vue d'ensemble du dépôt de vases de la structure 58 (photo : K. Meunier). 


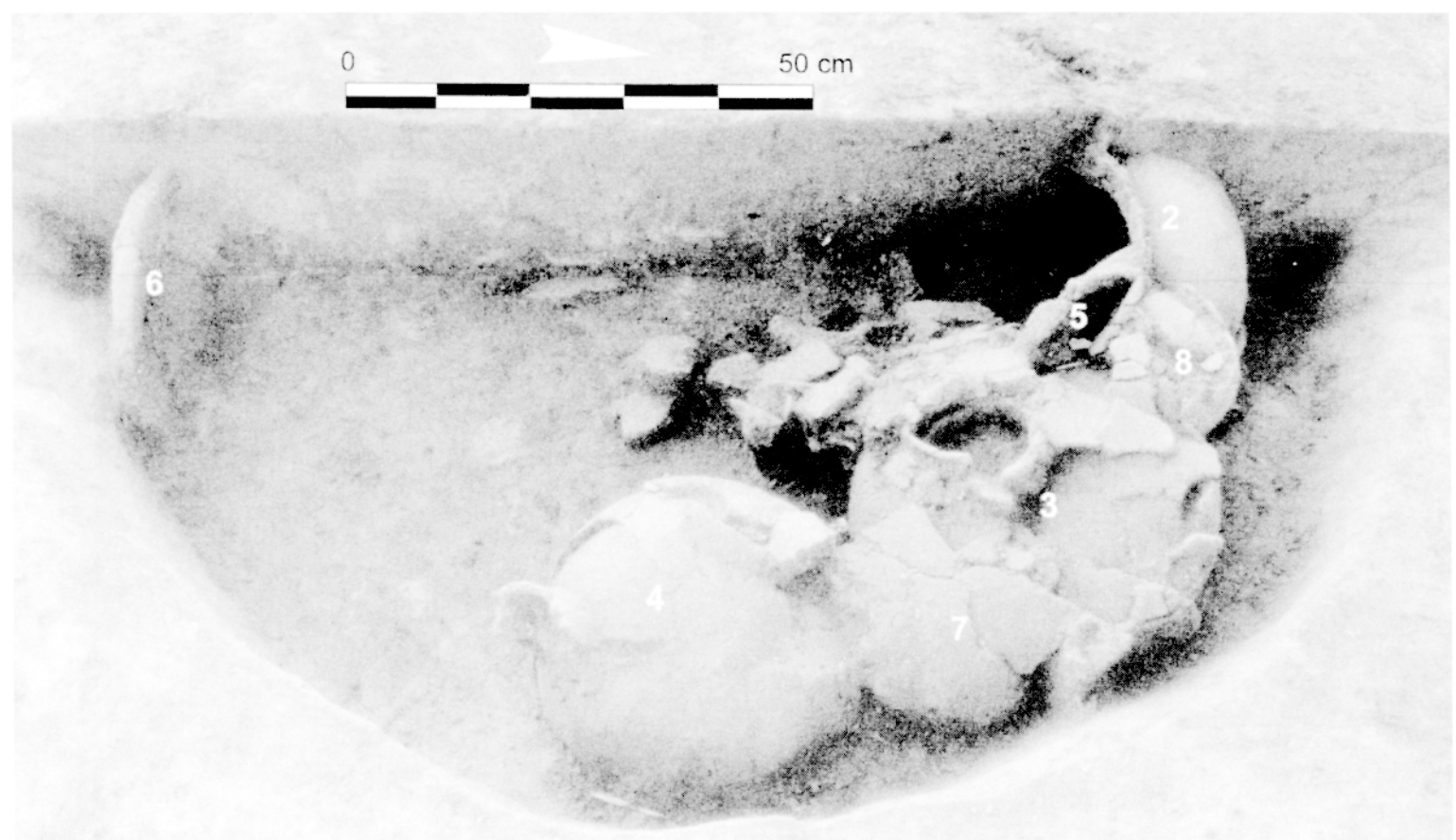

Fig. 9 - Partic est du dépôt de vases de la structure 58 (photo : K. Meunier).

l'épaisseur varie de 1,5 à $2,5 \mathrm{~cm}$. La pâte est systématiquement dégraissée, les inclusions étant le plus souvent apparentes. Le dégraissant le mieux représenté est le sable composé de quartz en fraction plus ou moins fine. Il est particulièrement abondant et grossier (2-5 mm) dans les deux disques en terre cuite. La coquille pilée grossièrement $(2-5 \mathrm{~mm})$ a été utilisée pour les grands vases tulipiformes, dans un cas associée à du quartz. La chamotte fine est attestée dans deux cas, la coupe en demi-sphère et une bouteille.
Les techniques de montage sont lisibles sur quelques vases. Le montage au colombin est assuré pour les cols et la partie supérieure des panses, d'après les différences d'épaisseur et le décollement systématique des cols. Les fonds sont fréquemment bosselés. Les surfaces sont toujours très bien lissées, parfois même polies, en particulier à l'extérieur des vases. Sur deux vases, le polissage est plus détérioré sur la partie inférieure que le reste de la panse. Les deux disques en terre cuite ont manifestement été fabriqués à partir

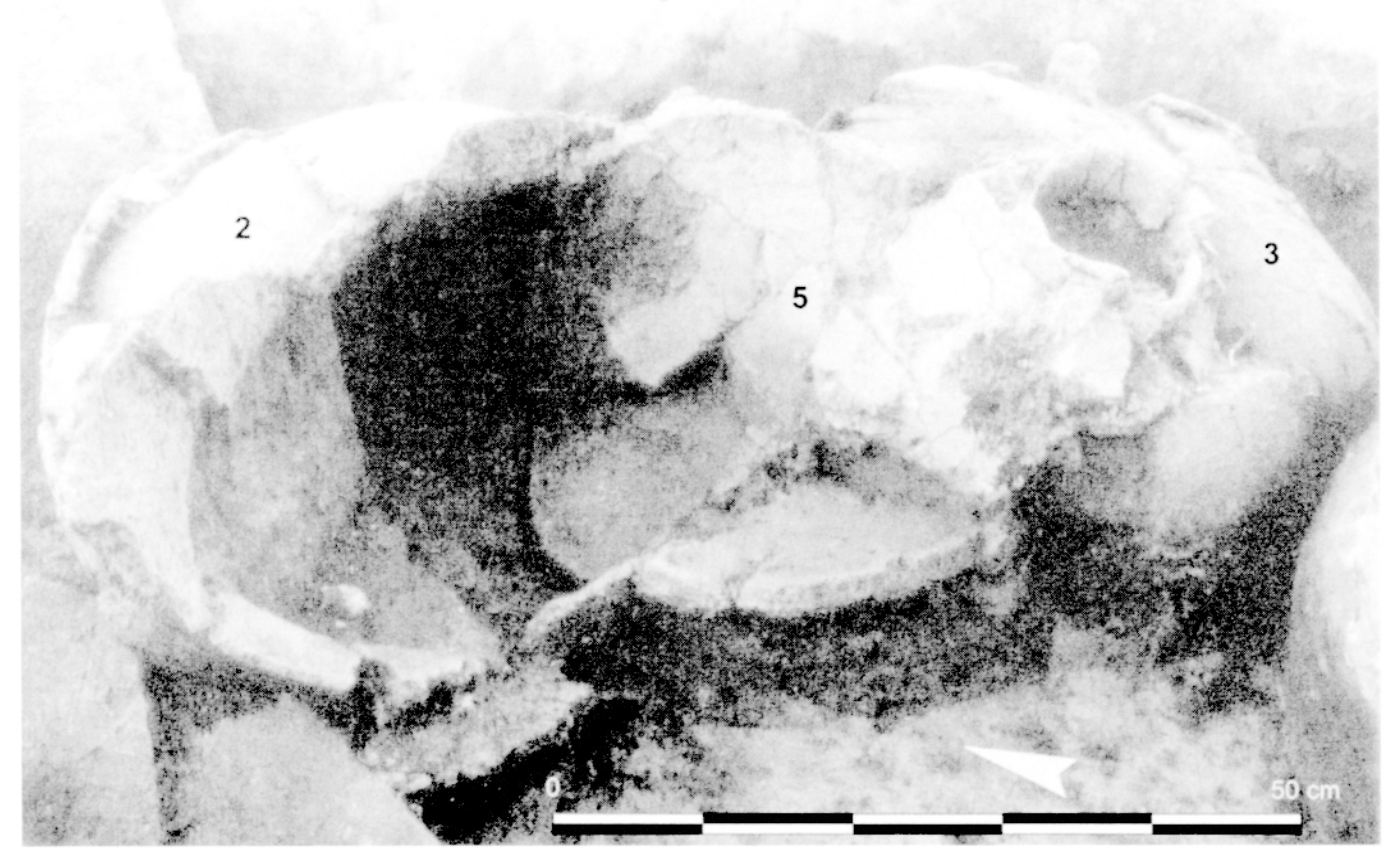

Fig. 10 - Détail du dépôt de vases de la structure 58 (photo : K. Meunier). 
d'une seule plaque, les traces de double plaque ou de colombin spiralé étant inexistantes. L'un des deux a été moulé sur une vannerie spiralée (fig. 13).

À l'exception des disques en terre cuite qui possèdent une pâte très friable, les vases se caractérisent par un matériau solide et bien conservé résultant d'une bonne cuisson. Les couleurs montrent une tendance à la cuisson réductrice, avec des pâtes gris-brun à noir au cœur, hormis les deux disques en terre cuite à pâte rouge. Les observations des vases complets ont permis de relever l'uniformité de la couleur des surfaces intérieures, qui peuvent être beiges, brunes ou noires, alors que la surface extérieure d'un même vase peut varier du beige au brun, avec des plages noires.

\section{Caractères morphométriques et décoratifs}

Chaque type de vase de la structure 58 est décrit et comparé aux systèmes chronologiques déjà établis : la chronologie du Michelsberg de J. Lüning (1968) et la division du groupe d'Entzheim en deux étapes de C. Jeunesse (1982).

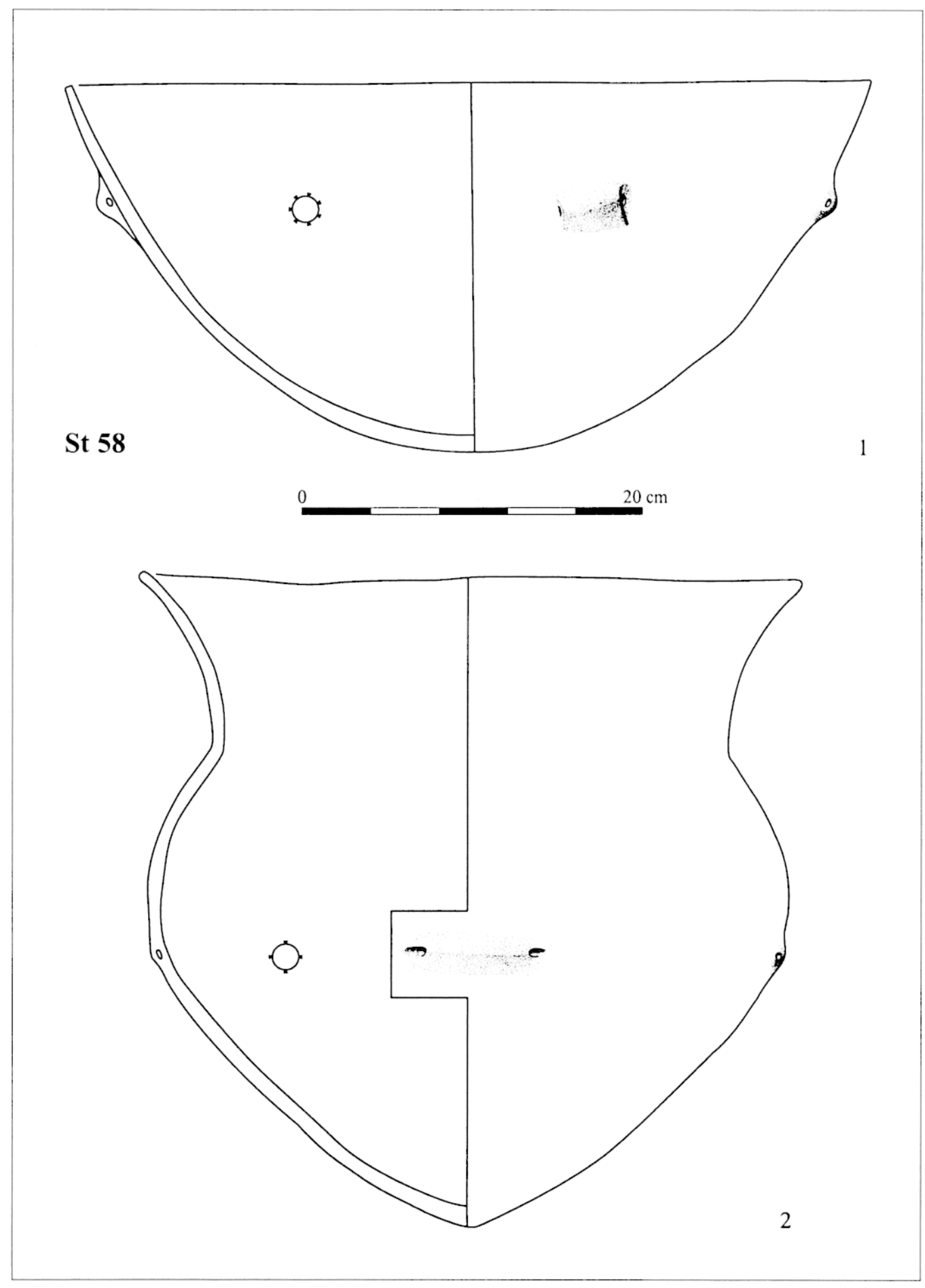

Fig. 11 - Céramique de la structure 58 (dessin : J.-L. Issele, Inrap/P. Girard, Inrap). 
- Coupe en calotte hémisphérique (fig. 11, $n^{\circ} 1$ ) : cette catégorie est représentée par un seul vase, de très grande taille $(\mathrm{D}$ ouv. $=46 \mathrm{~cm}: \mathrm{H}=22 \mathrm{~cm})$ portant sept anses tubulaires. Cette forme, associée à des dimensions aussi importantes, nexiste pas dans le groupe d'Entzheim. ni dans le Michelsberg, où les grands vases ouverts attestés sont beaucoup plus bas et fréquemment carénés. Le vase de Pfulgriesheim se rapprocherait plus des coupes en calotte du Chasséen méridional (Vaquer, 1991, fig. 4. $n^{\circ}$ 7; Clottes et Giraud. 1991, fig. 2, $n^{\circ} 4$ ).

- Vases à col ou vases tulipiformes : au sein de cette catégorie, l'unique vase complet non décoré est de très grande taille $(\mathrm{DM}=36 \mathrm{~cm}: \mathrm{H}=39 \mathrm{~cm})$ et se caractérise par un fond conique et quatre anses tunnelliformes légèrement en dessous du diamètre maximum de la panse (fig. $11, \mathrm{n}^{\circ} 2$ ). Il se rapproche des Tulpenbechern type 1.2 (Lüning. 1968) mais son fond se distingue par sa forme plus conique. Un second individu non décoré est représenté par un fragment de bord non mesurable. Les trois autres vases à col sont décorés d’impressions ongulées ou digitées sous le bord (fig. 14, $\mathrm{n}^{\circ} 5$ à 7), celui-ci étant épaissi dans deux cas. Les diamètres à l'ouverture sont de 20, 24 . et $27 \mathrm{~cm}$.

- Bouteilles : une des bouteilles complètes est non décorée (fig. 14. $\mathrm{n}^{\circ} 1$ ) et de grande taille $(\mathrm{DM}=30 \mathrm{~cm}$; $\mathrm{H}=40 \mathrm{~cm})$. Elle est de forme ovoüde, avec un col peu évasé, et une couronne d'éléments de préhension/ suspension placée sous le diamètre maximum de la panse. Elle est comparable aux Ösenkranzflaschen de type 1.2 mais rappelle aussi le type 2 par sa forme ovoïde. La bouteille complète décorée (fig. 12, $\mathrm{n}^{\circ} 1$ ) est de forme globulaire avec une base légèrement aplatie et porte quatre anses sous le diamètre maximum de la panse $(\mathrm{DM}=33 \mathrm{~cm}, \mathrm{H}=33 \mathrm{~cm})$. Le décor est incisé et occupe la moitié supérieure de la panse : il se compose d'un décor couvrant constitué de deux bandes horizontales de chevrons encadrant un panneau de damiers et de bandes verticales sous-jacentes remplics de hachures obliques. La forme générale du vase est affiliée aux bouteilles à panse sphérique du groupe d'Enthzeim. bien que la partic inférieure de la panse soit plus étirée. Quelques tessons décorés devaient probablement appartenir à une troisième bouteille (fig. $14, n^{\circ} 2$ ). Le décor restitué est composé d'un décor horizontal imprimé à la tige creuse situé au niveau de la jonction du col et de la panse et d'un décor sous-jacent constitué d'incisions verticales parallèles.

- Cruche : plusieurs tessons permettent de restituer une cruche à profil segmenté et à fond plat ( $D$ ouv. $=9 \mathrm{~cm}$ ). munie d une anse large en ruban partant immédiatement sous le bord (fig. 14, $n^{\circ} 3$ ). Elle caractérise difficilement une étape précise puisque ce type se manifeste pendant toute la durée du Michelsberg.

- Disques en terre cuite : deux exemplaires possèdent un diamètre de 36 et $42 \mathrm{~cm}$ avec un bord épaissi. Ils sont tous deux décorés d'impressions digitées sur le contour. L'un des deux disques est décoré d'impressions profondes réalisées au poinçon sur le pourtour de la face plane (fig. $12, n^{\circ} 2$ ). Le second montre sur sa face inférieure les impressions d'une vannerie spiralée (fig. 13). Un seul fragment fait apparaître les empreintes des brins s'enroulant sur les spires.

- Puisoir : un seul individu, auquel il manque le tenon. est attesté (fig. 14, $n^{\circ} 4$ ).

\section{Signification chronoculturelle}

Par l'association d'éléments du groupe d'Entzheim et du Michelsberg, l'assemblage de vases de la structure 58 se révèle caractéristique de la seconde étape du groupe d'Entzheim. Celui-ci a été défini en Basse-Alsace et dans le nord du Kaiserstuhl par une combinaison d'éléments épi-Rössen, Michelsberg et chasséens (Schmitt, 1974). Puis une division en deux étapes a été établie par C. Jeunesse (Jeunesse, 1982) : l'étape A se caractérise par une abondance de décors en damier, triangles, chevrons, réalisés par incisions, impressions en pointillé-sillonné, et des décors de pastilles; l'étape B voit les décors incisés supplanter les décors imprimés parallèlement à l'intégration d'éléments $\mathrm{Mi}$ chelsberg, parmi lesquels vases tulipiformes et disques en terre cuite sont les plus marqués. Ces derniers permettent de synchroniser la fin du groupe d'Entzheim avec le Michelsberg II.

Au sein de l'assemblage du dépôt de vases, la composante Michelsberg domine. Neuf vases sur douze peuvent être attribués soit au Michelsberg sans précision. soit à une étape de celui-ci. Les grands vases tulipiformes, non décorés ou à bord épaissi digité, et la bouteille ovoïde à couronne d'éléments de préhension/ suspension se rapprochent des formes de l'étape II de la chronologie de Lüning, avec quelques nuances. Cependant, leur fond à tendance conique les différencient des types correspondants de l'étape II et évoque, en particulier pour la bouteille à couronne de préhension, certains types attribués à l'étape III. Le puisoir et les disques en terre cuite sont fréquents dans le Michelsberg mais ne permettent pas de définir une étape spécifique. Concernant ces derniers, les impressions au poinçon sur le pourtour de l'un des disques est rare mais trouve des équivalents en contexte Michelsberg (Laurelut, 1989, fig. 31, n 7 ; Reiter, 1998, fig. 4. $\mathrm{n}^{\circ} 4$; Lüning. 1968, pl. 105, $\mathrm{n}^{\circ} 2$ ). Les disques en terre cuite avec des empreintes de vannerie sur une face, sans être fréquents, sont bien attestés et montrent une variabilité des types de vannerie. Les empreintes de vannerie spiralée, telles qu'elles existent à Pfulgriesheim, sont comparables à celles d'Entzheim (Schmitt, 1987. pl. 6, $\mathrm{n}^{\circ} 5$ ) et à certains exemplaires attribués au Michelsberg (Lüning. 1968, pl. 105, $\mathrm{n}^{\circ}$ 5). Enfin, la cruche est difficilement représentative d'une étape donnée puisqu'on la trouve sporadiquement dans le Néolithique récent de la Basse-Alsace en général.

Les éléments caractéristiques du groupe d’Entzheim sont représentés par deux bouteilles décorées. La bouteille décorée d'un thème couvrant incisé associant damier, chevrons et bandes verticales hachurées est caractéristique du groupe d'Entzheim (fig. 12. $\mathrm{n}^{\circ} \mathrm{1}$ ). Cependant, deux éléments différencient ce vase des bouteilles décorées habituelles. Contrairement aux panses sphériques, cette bouteille possède une partie inférieure à tendance ovoïde et se rapproche par ce biais des 


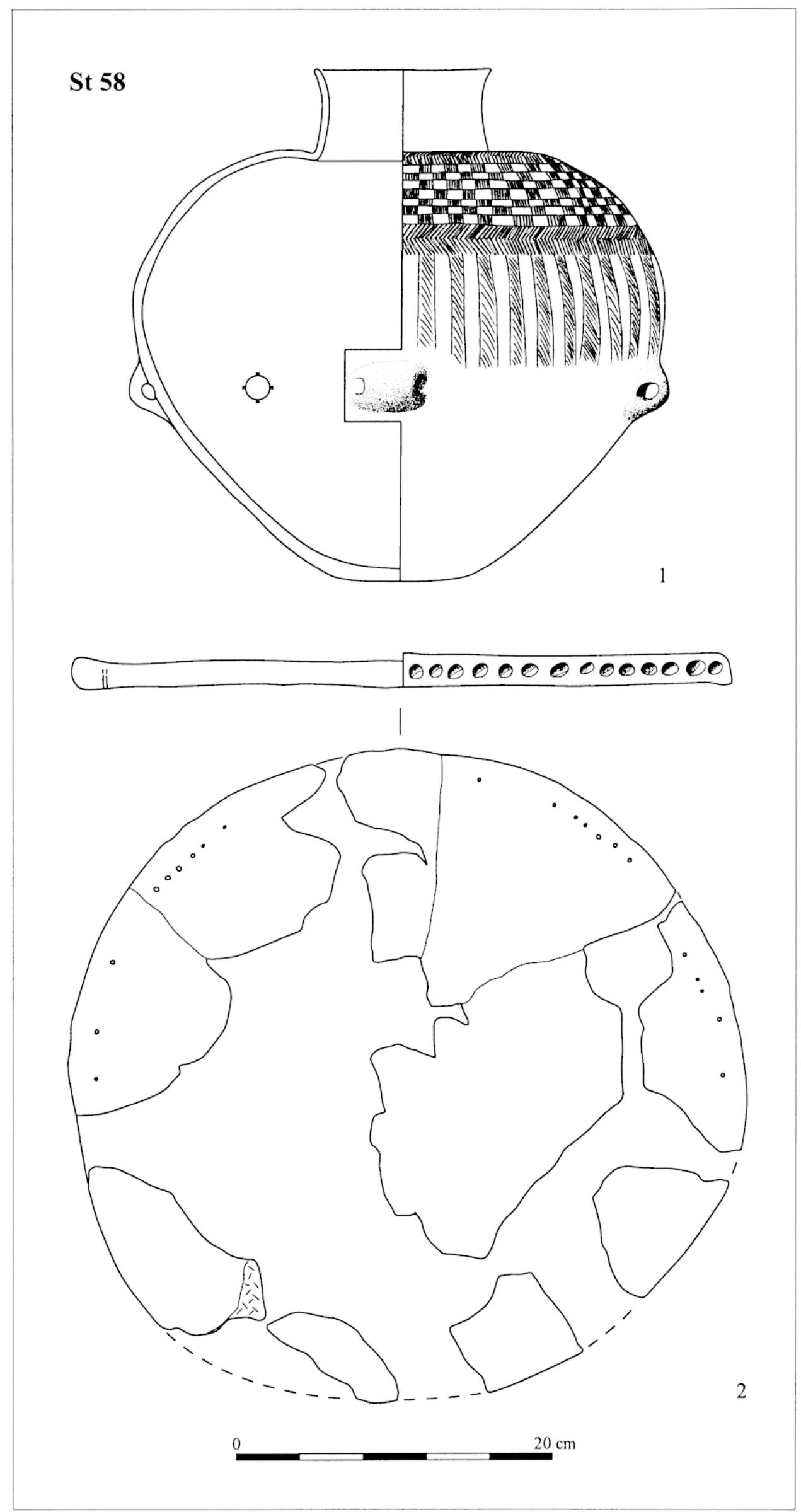

Fig. 12 - Céramique de la structure 58 (dessin : K. Meunier). 


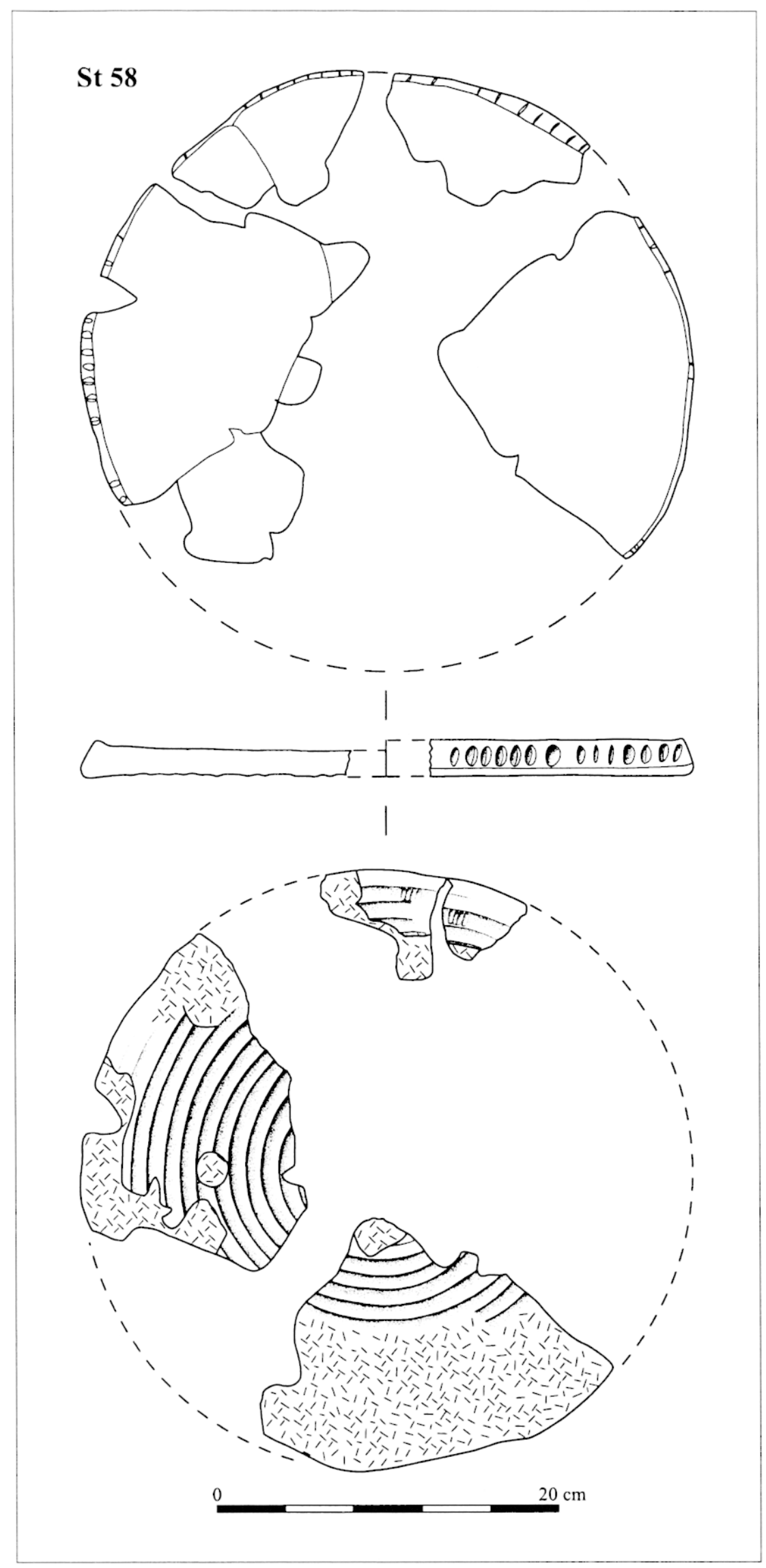

Fig. 13 - Céramique de la structure 58 (dessin : K. Meunier/P. Girard, Inrap). 


\section{St 58}
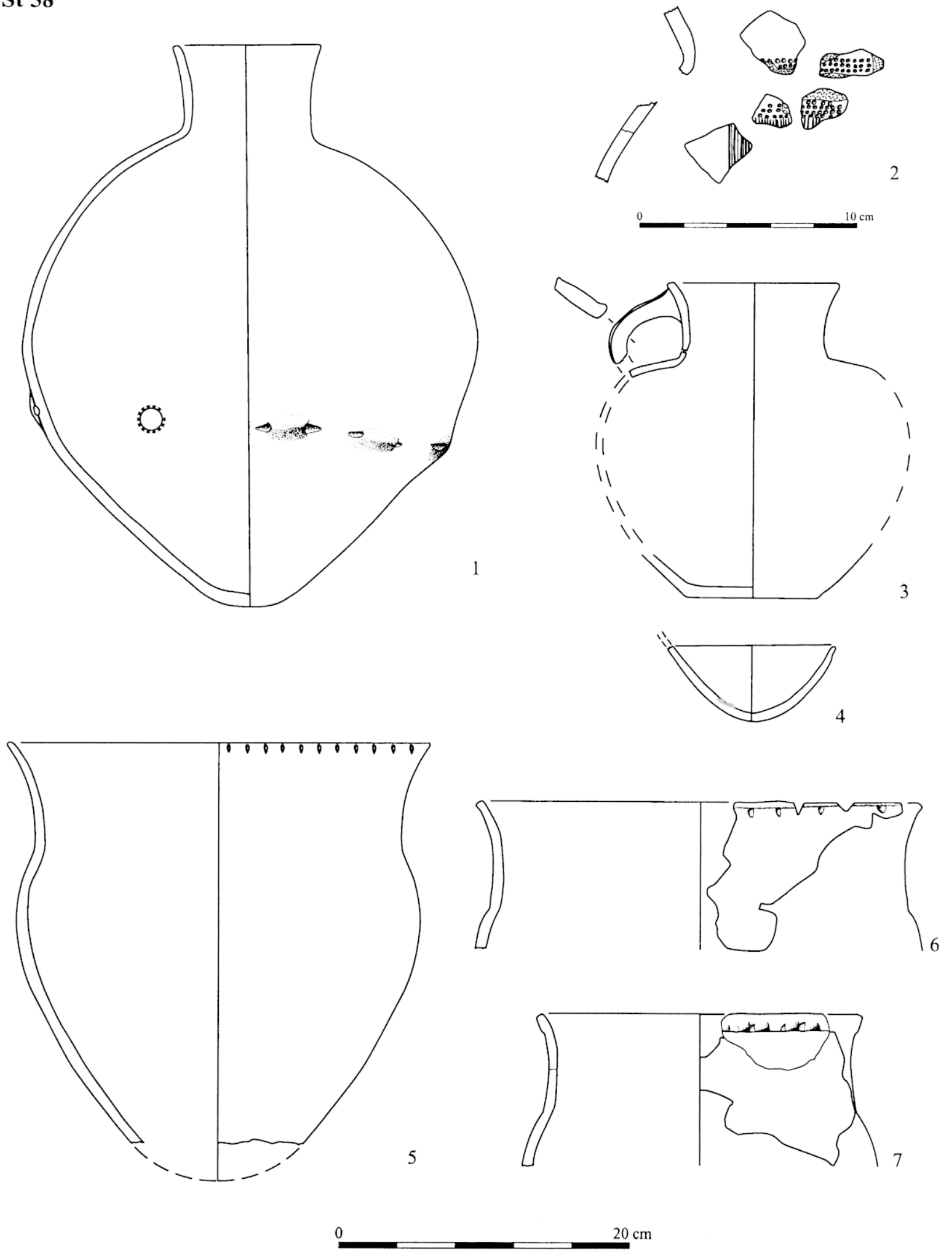

Fig. 14 - Céramique de la structure 58 (dessin : $n^{\text {os }} 1$ et $5: \mathrm{J}$.-L. Issele, Inrap/P. Girard, Inrap; $\mathbf{n}^{\text {os }} 2$ à 4,6 et $7: \mathrm{K}$. Meunier/P. Girard, Inrap). 
bouteilles classiques du Michelsberg. De plus, l'absence de pastilles à la jonction du col et de la panse est ici atypique puisque les pastilles, obtenues par différentes techniques, ornent toujours les bouteilles et les vases à col portant ce type de décor, notamment à Hochfelden (Sainty et Thévenin, 1977, fig. 3), Geispolsheim "Bruechel” (Koenig, 1988, fig. 2), Entzheim (Schmitt, 1974, pl. VII, VIII, XVIII, XX et XXV), Rosheim (Stahl, 1978, fig. 2, $\mathrm{n}^{\circ}$ 2) et Bischoffsheim (Lefranc et al., 2001). Dans le contexte de cette fosse, comportant un assemblage de vases à forte dominante Michelsberg, on peut envisager l'absence des pastilles comme un abandon. Celui-ci serait révélateur de l'aspect tardif de l'assemblage par rapport à l'étape B du groupe d'Entzheim. Enfin, le décor imprimé à la tige creuse associé à des incisions verticales (fig. 14, $\mathrm{n}^{\circ} 2$ ) est peu courant dans le Bas-Rhin où il est néanmoins attesté à Achenheim (Schmitt, 1974, pl. XXXV); il est plus répandu dans la région du Kaiserstuhl (Dieckmann, 1990, fig. $19, \mathrm{n}^{\circ} 11$ et fig. $22, \mathrm{n}^{\circ} 18$ ), où il est caractéristique du groupe de Wauwil.

\section{Interprétation du dépôt et comparaisons}

La diversité des formes de l'assemblage de la structure 58 est marquante : bouteilles, vases tulipiformes, coupe, puisoir, cruche, disques en terre cuite. Cet ensemble est représentatif des formes classiques de la fin du Néolithique moyen et fournit un répertoire fonctionnel varié. À l'exception du puisoir, la grande taille des récipients (diamètres maximum échelonnés entre 24 et $47 \mathrm{~cm}$ ) est cependant atypique. Si l'on considère les autres structures du site, les vases y sont exclusivement de petite taille. La distribution spatiale entre petits et grands vases est donc très contrastée. Les vases de grande taille de la structure 58 sont aussi surreprésentés par rapport aux autres corpus épiRössen et Michelsberg. Les diamètres maximum de certains vases figurent parmi les plus importants des grandes séries de vases Michelsberg du Bassin parisien, comme Bazoches, Mairy, Noyen, où les vases de 30 à $35 \mathrm{~cm}$ sont très minoritaires, et ceux de plus de $40 \mathrm{~cm}$, exceptionnels (Colas, 2000, pl. 3, $\mathrm{n}^{\mathrm{os}} 17$ et 29). Aussi, les diamètres du disque en terre cuite $n^{\circ} 6$ $(42 \mathrm{~cm})$, du vase ouvert en calotte $(46 \mathrm{~cm})$ et du vase tulipiforme $\mathrm{n}^{\circ} 2(36 \mathrm{~cm})$ n'ont-ils pas d'équivalent. De même, les dimensions de la bouteille complète portant un décor Entzheim $(\mathrm{DM}=33 \mathrm{~cm}, \mathrm{H}=33 \mathrm{~cm}$ ) dépassent celles de toutes les bouteilles décorées de ce groupe. On est donc en présence d'un ensemble dont la taille des vases est significative. Elle pourrait évoquer aussi bien une fonction de stockage que de présentation à usage collectif.

Dans le cadre de l'interprétation chronologique du dépôt de vases, l'analyse de phénomènes comparables dans des contextes Michelsberg ou à composante Michelsberg est déterminante. Bien que le dépôt de Pfulgriesheim fasse figure d'exception dans la sphère de l'épi-Rössen et du Michelsberg, il existe cependant des structures comparables dans le Bassin parisien. Celles-ci comportent des vases presque complets mais toujours brisés, précisément la fosse 385 de Cuiry-lès-Chaudardes (Lasserre et
Lebolloch, 1982) et plusieurs fosses-silos du site de Mairy (Marolle, 1989). Ces vases se présentent dans les deux sites sous forme d'une épaisse couche de tessons imbriqués les uns dans les autres. Des dépôts intégrés à d'autres types de contextes sont aussi à prendre en compte. En effet, à Bazoches-sur-Vesle (Dubouloz et al., 1997), des zones de rejets massifs sont concentrés sur quelques mètres d'une portion donnée de l'enceinte; des vases entiers semblent aussi avoir été déposés. Le site de Noyen-sur-Seine comprend également des vases entiers dans certains fossés de palissades (Henocq-Pochinot et Mordant, 1991). La mise en parallèle avec les restes osseux d'animaux sous forme d'importants amas et d'épandages, en particulier à Mairy (Arbogast, 1998), montre aussi une même tendance dans la spécificité des rejets ou des dépôts.

L'interprétation du dépôt de Pfulgriesheim n'est pas évidente mais son aspect symbolique laisse peu de doute. Il témoigne de l'intensification de comportements à caractère symbolique qui semble marquer le début du Michelsberg dans des sites bien spécifiques, jusqu'à maintenant surtout documentés dans le Bassin parisien. Les sites de Mairy, Bazoches-surVesles, Cuiry-lès-Chaudardes et Noyen-sur-Seine en sont les principaux représentants. Ces manifestations sont d'ailleurs répandues dans le Néolithique moyen II (chronologie française) en général, si l'on considère le Chasséen méridional où l'existence de dépôts de vases entiers est attestée à Saint-Paul-Trois-Châteaux (Beeching, 1991).

\section{La céramique des autres fosses}

Les structures $49,50,55,56,59$ et 70 comportent 17 individus, dont 11 formes reconstituées.

\section{Caractères techniques}

Le matériau des vases des structures de l'ensemble du site ne diffère pas de celui de la structure 58 . Le dégraissant inclus dans la pâte comprend du quartz, de la coquille pilée et de la chamotte. Les surfaces sont toujours bien lissées. Excepté un fragment de disque en terre cuite à pâte orangée, la pâte est brune ou noire au cœur. La couleur des surfaces varie du beige au brun-noir, avec parfois des teintes rouges ou orangées.

\section{Caractères morphométriques}

Hormis quatre bords de forme indéterminée, un tesson de vase à paroi segmentée (st. 45) et un tesson caréné (st. 49), le corpus céramique issu des autres fosses situées à proximité de la structure 58 regroupe les formes suivantes :

- deux puisoirs (fig. 15, $\mathrm{n}^{\mathrm{os}} 2$ et 5), dont le premier est complet avec un tenon large de section plate (D ouv. : $8 \mathrm{~cm}$ );

- un petit vase tulipiforme à fond conique (fig. 15, $\left.\mathrm{n}^{\circ} 4\right)(\mathrm{DM}=11 \mathrm{~cm} ; \mathrm{H}=12,5 \mathrm{~cm})$;

- deux vases à profil sinueux (fig. $15, \mathrm{n}^{\text {os }} 1$ et 8) (DM $=14$ et $18 \mathrm{~cm}$ ); 


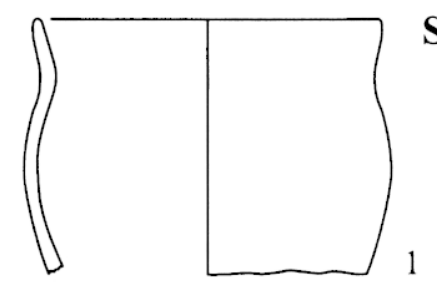

St 49
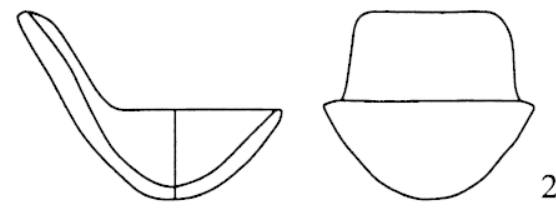

0000

1
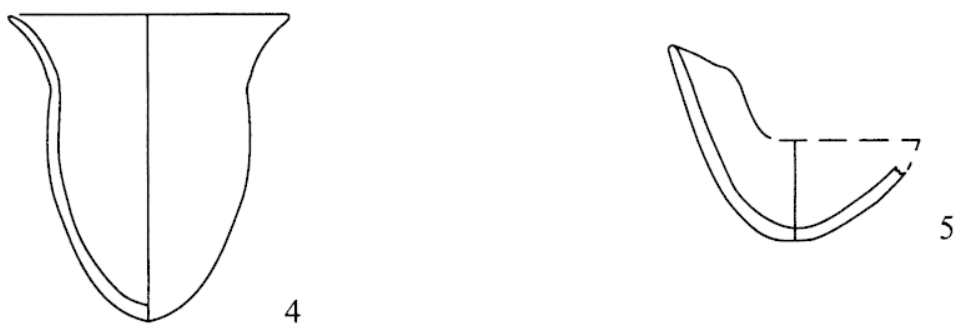

4

\section{St 59}

\section{St 56}
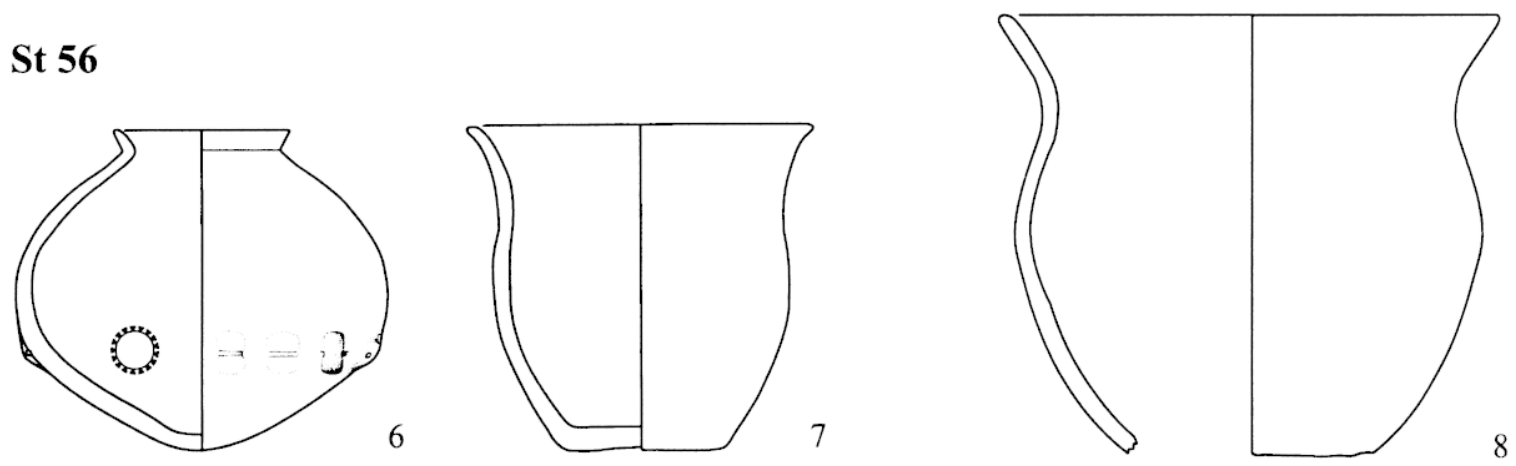

\section{St 50}

\section{St 70}
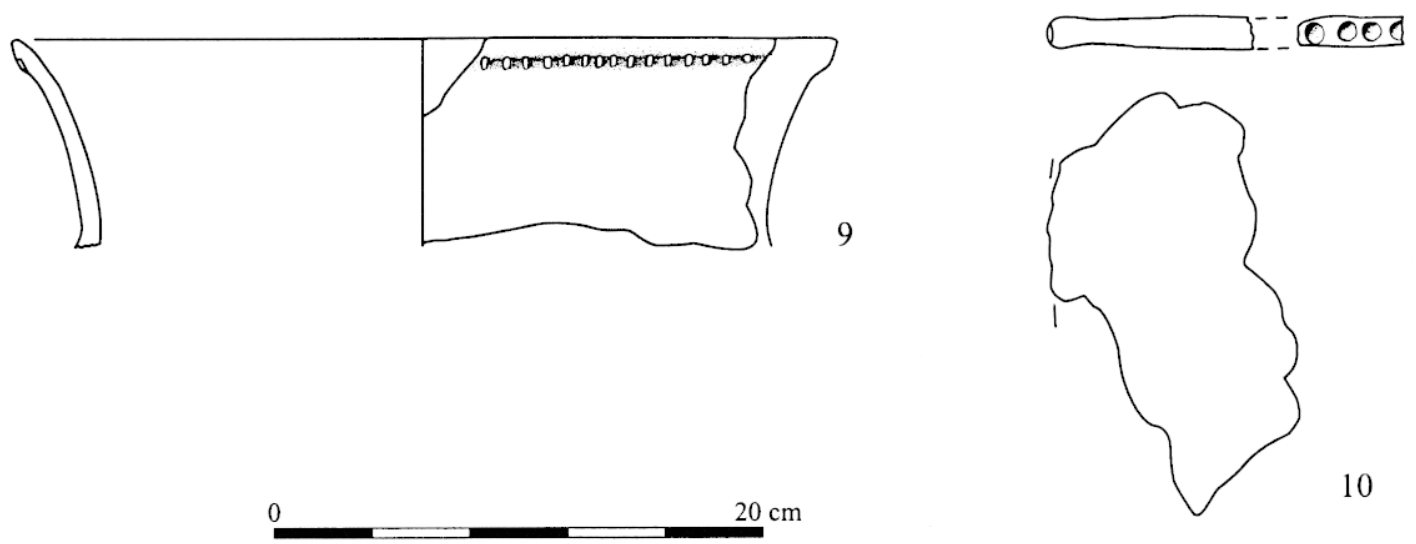

Fig. 15 - Céramique des structures 49, 55, 56, 59, 50, et 70 (dessin : K. Meunier/P. Girard, Inrap).

- un vase à col évasé décoré de pincements sur le rebord épaissi (fig. $\left.15, \mathrm{n}^{\circ} 9\right)(\mathrm{D}$ ouv. $=26 \mathrm{~cm}$ );

- trois fragments de disque en terre cuite dont deux sont décorés d'impressions digitées sur le contour (fig. $15, \mathrm{n}^{\text {os }} 3$ et 10 );
- un vase à col évasé et fond plat légèrement convexe (fig. 15, $\left.\mathrm{n}^{\circ} 7\right)(\mathrm{DM}=14 \mathrm{~cm} ; \mathrm{D}$ ouv. $=11 \mathrm{~cm} ; \mathrm{H}=$ $13 \mathrm{~cm})$;

- un vase fermé à col court éversé, à panse ellipsoïdale et fond conique, portant une couronne d'éléments 
de préhension/suspension placée sous le diamètre maximum de la panse (fig. $15, \mathrm{n}^{\circ}$ 6) $(\mathrm{DM}=11 \mathrm{~cm}$ : D ouv. $=10.5 \mathrm{~cm}: \mathrm{H}=13.5 \mathrm{~cm})$.

\section{Interprétation chronologique}

Ces formes, distribuées de une à trois par fosse, peuvent difficilement donner des indications très précises sur la chronologie. La plupart existent indifféremment dans le groupe d'Entzheim et pendant toute la durée du Michelsberg : les puisoirs par exemple, les vases tulipiformes et les disques en terre cuite. En revanche. dans la structure 56. l'association d'un vase à profil sinueux et à fond plat avec un vase à col court éversé et à fond conique portant une couronne de boutons perforés est à retenir. Ce type d'association a déjà été remarqué à Lingolsheim "Ficht" en contexte Michelsberg ancien (Jeunesse, 1989, fig. 7). De plus, le type de forme avec bord éversé et couronne de boutons perforés est répandu jusque dans le Michelsberg ancien du Bassin parisien, à Mairy (Laurelut, 1989, fig. 29, $\mathrm{n}^{\circ} 5$ ). Le vase à fond plat, peu fréquent dans cet horizon chronologique, est par ailleurs attesté dans une série Entzheim final, à Geispolsheim "Bruechel" (Koenig, 1988, fig. 2). D'après les caractères de ces deux vases, il est vraisemblable que la structure 56 soit contemporaine de la structure 58 .

\section{Le mobilier lithique}

Le mobilier lithique est peu abondant. Il comprend seulement deux éclats de silex, une boucharde en roche verte grossière (fig. $16, n^{\circ} 2$ ), ainsi que quatre fragments de pièces en grès, dont l'un est un fragment de meule ou de molette.

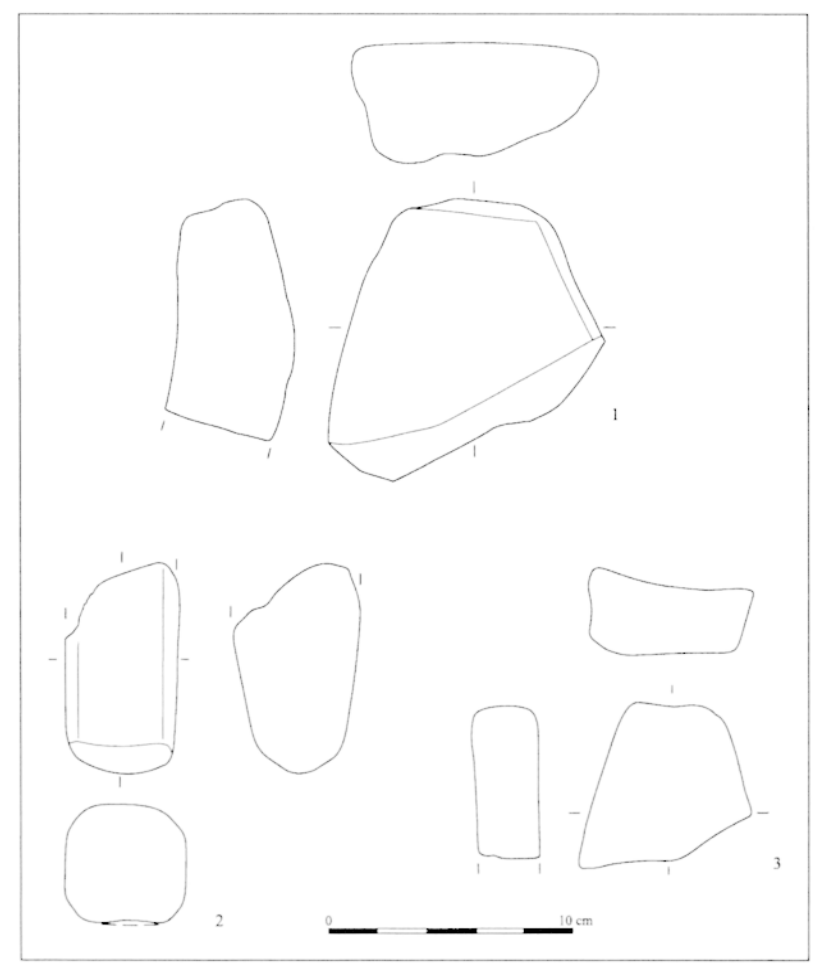

Fig. 16 - Matériel lithique. $N^{\circ} 1:$ structure $49: n^{\prime \prime} 2$ et $3:$ structure 50 (dessin : K. Meunier/P. Girard. Inrap).
Une molette. issue de la structure 49, est brisée en largeur et fabriquée dans un grès fin gris-rose (fig. 16. $\mathrm{n}^{\circ} 1$ ). Elle est de forme ovoïde et de section asymétrique. Le dos a été aménagé par enlèvements. La surface active est légèrement concave longitudinalement et convexe transversalement. La surface active présente des traces de piquetage sur toute la surface, sousjacent à un poli intense.

Deux fragments de polissoir sont tous deux réalisés dans un grès beige à rose compact et très fin (st. 50). Le premier, brisé en largeur, est de forme ovale à extrémité aplatie (fig. 16, $\mathrm{n}^{\circ} 3$ ). De section rectangulaire avec un dos plat, la surface active est concave. Les surfaces sont très régulières et lisses et la surface active lustrée vers les bords. Le second polissoir, aussi fragmenté, possède un dos plat et une surface active moins incurvée que le premier.

\section{L'industrie osseuse}

Deux fosses ont livré trois pièces de mobilier osseux dont on trouvera la description ci-dessous. Au contraire du Rubané, l'industrie osseuse de cette période est mal documentée. Néanmoins, l'étude de corpus fournis émaillés dans l'espace, groupe de Menneville (Berry-au-Bac), Michelsberg (Maizy, Cuiry-lès-Chaudardes), Chasséen septentrional (Boury, Catenoy et Louviers) (Sidéra, 2000a) et méridional (Montou, Corbères-les-Cabanes) (Sidéra, à paraître b) et Cortaillod (Montilier Fischergässli) (Sidéra, 2000b), permet de commencer à mieux cerner les différents visages de la technologie et des utilisations des matières osseuses des complexes culturels de cette époque. Les quelques documents livrés par les fosses de Pfulgriesheim ne sont pas inintéressants.

Structure 58, objet 1 (fig. $17, \mathrm{n}^{\text {os }} 2$ et 4 ) : canine de canidé d'un bon état de conservation. L'objet est brisé en biais depuis la base de la racine jusqu'à la pointe de la partie émaillée. Elle comporte probablement deux aménagements : un forage perpendiculaire à la racine et centré sur l'une des faces les plus larges de la racine, un méplat artificiel. Ce dernier résulte peut-être d'une abrasion de la face vestibulaire de la racine. Les restes de cette abrasion, en grande partie émoussée et polie en biais (fig. $17, \mathrm{n}^{\circ} 2$ ), sont peutêtre sensibles à la loupe à la périphérie de la plage. L'autre face présente aussi un poli diagonal sur la racine jusqu'à la base de l'émail mais moins développé. Le contour de la perforation, en ovale, est déformé par usure : un surcreusement bilatéral émoussé et poli. En profil, un léger ensellement manifeste la perforation. Les déformations de la perforation et de la racine suggèrent un fort degré d'usure de la perle, produit par le frottement d'une couture pratiquée de chaque côté de la perforation. L'aménagement du méplat a été réalisé pour présenter l'objet de face et faire en sorte que ce décor soit visible. De tels aménagements ont déjà été observés sur des séries de craches de cerf perforées du $\mathrm{III}^{\mathrm{e}}$ millénaire et disposées de la même manière, à plat sur un support souple constituant à l'identique une parure de vêtement (Sidéra, 2000c et à paraître a). 
Comme en témoigne le poli présent sur ses deux faces, qui reflète le voisinage de la perle avec d'autres objets, il est vraisemblable que cet objet ait été associé à d'autres pour élaborer la parure composite d'un vêtement ou d'un collier monté sur lanière. Peut-être, avec l'autre perle, les deux objets faisaient-ils partie d'un même ensemble? Les canines de canidé ne sont pas représentatives d'un contexte culturel donné car elles sont répandues. La fréquence de leur utilisation croît cependant avec le développement du Néolithique. Si elles deviennent fréquentes à partir du Grossgartach seulement, elles semblent se développer plus encore durant le plein Néolithique moyen, récent et final (Sidéra, 2000a, p. 150-154). Avant cette période, leur présence n'est pas significative.

Structure 58, objet 2 (fig. $17, n^{\text {os }} 3$ et 4 ) : c'est une canine de canidé, d'un état de conservation médiocre, dont le seul aménagement est une perforation perpendiculaire de la racine pratiquée pour constituer une perle. Celle-ci, brisée à hauteur des parois latérales de la perforation, ne permet pas d'apprécier directement la nature de l'usure. Toutefois, la minceur des parois restantes de la perforation évoquent un degré d'usure bien développé et responsable de la cassure de l'objet : une perle probablement cousue sur un vêtement ou une lanière.

Structure 59, objet 3 (fig. $17, \mathrm{n}^{\circ} 1$ ) : outil perforant entier fabriqué à partir d'un métatarse de capriné scié en deux dont un segment d'épiphyse distale a été conservé en guise de poignée (longueur $=100 \mathrm{~mm}$ ). La pièce présente un mauvais état de conservation qui ne permet pas de lecture tracéologique fine. Elle comporte une pointe piquante amplement dégagée et déformée par rapport à l'initiale dont l'aménagement, façonnage et raffûtage, recoupe le sciage : signe de l'usage matériel de l'objet avant son enfouissement. Le sciage pratiqué pour la découpe a laissé quelques traces. Cet outil perforant, somme toute ordinaire, présente un type d'aménagement en revanche peu commun. Il s'agit d'une abrasion discrète de la crête centrale de l'épiphyse, faces palmaire et plantaire, qui brise sa courbe naturelle. De telles retouches de l'épiphyse, qui résultent peut-être de la manière dont la pièce a été travaillée, donc pleinement du savoir-faire, ne sont ni répandues ni aléatoires. Elles sont au contraire très typiques et restreintes aux outils perforants sciés en deux du groupe de Montbolo, du Chasséen méridional et du Cortaillod (Sidéra, 2000b et à paraître b). Il est frappant de constater qu'un outil fabriqué à la manière très typée de la Méditerranée figure en contexte aussi septentrional. La connaissance très limitée que nous avons de la technologie des matières osseuses dans les contextes culturels du Néolithique moyen alsacien interdit d'interpréter plus avant ce fait. Néanmoins, l'incidence des contextes Chasséen/Cortaillod/Lagozza est sûre pour cette pièce.

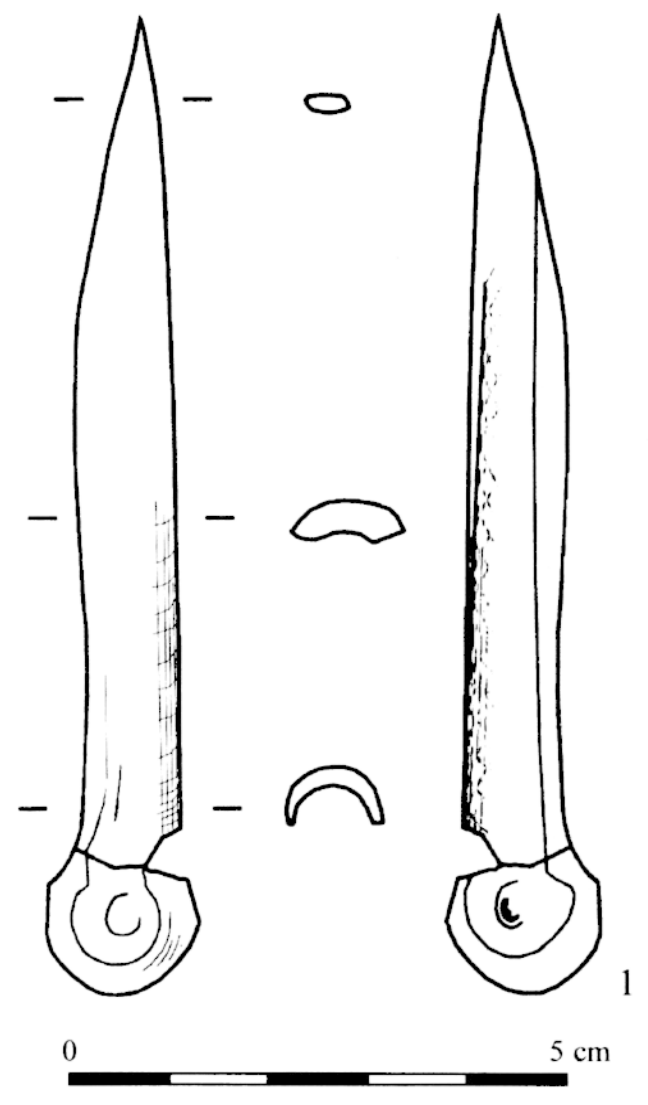

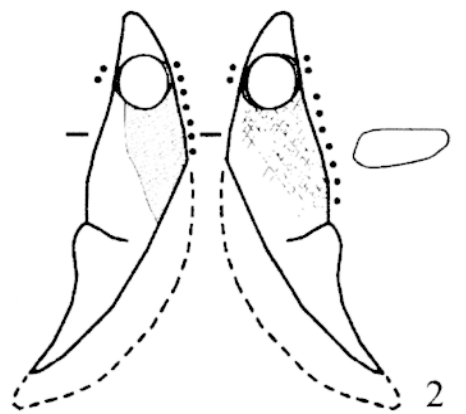
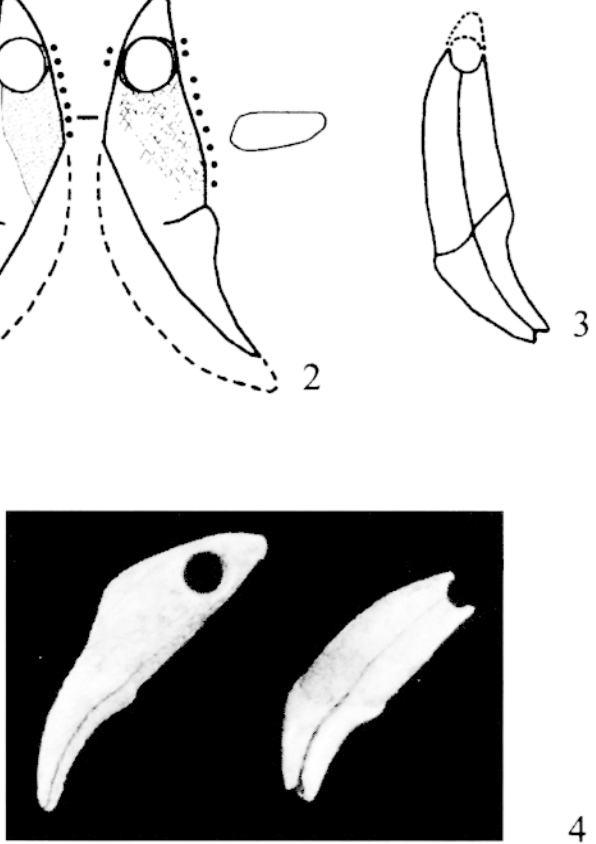

4

0 $5 \mathrm{~cm}$

Fig. 17 - Industrie osseuse. $N^{\circ} 1:$ outil perforant scié en deux, structure $59 ; n^{\circ} 2$ à 4 : parures sur canines de canidés, structure 58 (dessin : I. Sidéra: photo : F. Schneikert, Inrap). 


\begin{tabular}{|l|c|c|c|c|c|c|r|r|r|}
\hline NR & St. 45 & St. 49 & St. 50 & St. 56 & St. 58 & St. 59 & St. 70 & Total & \multicolumn{1}{c|}{} \\
\hline Bœuf & 2 & 1 & 1 & 6 & 3 & 11 & 3 & 27 & 17,76 \\
$\begin{array}{l}\text { Porc } \\
\text { Caprinés } \\
\text { Chien }\end{array}$ & 4 & 1 & & 1 & & & 112 & 118 & 77,63 \\
& & 2 & & & 3 & 1 & & 6 & 3,95 \\
1 & & & & 1 & & & 1 & 0,66 \\
\hline Total déterminés & $\mathbf{6}$ & $\mathbf{4}$ & $\mathbf{1}$ & $\mathbf{7}$ & $\mathbf{7}$ & $\mathbf{1 2}$ & $\mathbf{1 1 5}$ & $\mathbf{1 5 2}$ & 100,00 \\
\hline Indéterminés & & 4 & & & 29 & 16 & & 49 & \\
\hline TOTAL & $\mathbf{6}$ & $\mathbf{8}$ & $\mathbf{1}$ & $\mathbf{7}$ & $\mathbf{3 6}$ & $\mathbf{2 8}$ & $\mathbf{1 1 5}$ & $\mathbf{2 0 1}$ & \\
\hline PR (g.) & St. 45 & St. 49 & St. 50 & St. 56 & St. 58 & St. 59 & St. 70 & Total & $\%$ \\
\hline Bœuf & 52 & 228 & 97 & 158 & 188 & 298 & 94 & 1115 & 37,19 \\
Porc & 41 & 3 & & 97 & & & 1728 & 1869 & 62,34 \\
Caprinés & 4 & & & 4 & 2 & & 13 & 0,43 \\
Chien & & 7 & & & 1 & & & 1 & 0,03 \\
\hline Total déterminés & $\mathbf{9 3}$ & $\mathbf{2 3 8}$ & $\mathbf{9 7}$ & $\mathbf{2 5 5}$ & $\mathbf{1 9 3}$ & $\mathbf{3 0 0}$ & $\mathbf{1 8 2 2}$ & $\mathbf{2 9 9 8}$ & 100,00 \\
\hline Indéterminés & & 2 & & & 29 & 43 & & 74 & \\
\hline TOTAL & $\mathbf{9 3}$ & $\mathbf{2 4 0}$ & $\mathbf{9 7}$ & $\mathbf{2 5 5}$ & $\mathbf{2 2 2}$ & $\mathbf{3 4 3}$ & $\mathbf{1 8 2 2}$ & $\mathbf{3 0 7 2}$ & \\
\hline
\end{tabular}

Tabl. 2 - Décompte par espèce et par structure des restes de faune attribués au groupe d'Entzheim (NR : nombre de restes. PR : poids des restes).

\section{Les restes de faune}

Les vestiges osseux d'animaux des structures du Néolithique moyen/récent représentent un lot de faune d'environ 200 restes déterminés (tabl. 2 et 3 , annexe 2). Mais seul l'ensemble de la structure 70 comptabilise plus d'une centaine de restes. L'état de conservation des os est semblable à celui observé pour les restes de faune rubanés.

Les ossements issus des fosses attribuées au groupe d'Entzheim et plus particulièrement ceux de la structure 70, dans laquelle se concentrent la plupart des fragments, se présentent de façon similaire mais arborent aussi quelques spécificités. En effet, contrairement à ce qui s'observe le plus souvent en contexte de dépotoir, une part non négligeable des restes issus de cette structure ont pu faire l'objet de remontages et de reconstitutions d'appariements. Avec un taux de remontage de l'ordre de $20 \%$, cette structure est de ce point de vue même particulièrement remarquable. Les remontages les plus fréquents y concernent des recollages de cassures anciennes ainsi que des appariements sur mandibules, mais des cas de recollages de fragments d'os longs sont également attestés, sans compter les cas également nombreux, mais plus

\begin{tabular}{|l|c|}
\hline NR & St. 70 \\
\hline Crâne & 3 \\
\hline Dents supérieures & \\
\hline Mandibules & 11 \\
\hline Dents inférieures & \\
\hline Dents isolées & 1 \\
\hline Scapula & 5 \\
\hline Humérus & 4 \\
\hline Radius-Ulna & \\
\hline Carpes & 4 \\
\hline Métacarpes & 6 \\
\hline Coxal & 2 \\
\hline Fémur & 7 \\
\hline
\end{tabular}

\begin{tabular}{|l|r|}
\hline NR & St. 70 \\
\hline Patella & \\
\hline Tibia-Fibula & 1 \\
\hline Tarses & 1 \\
\hline Métatarses & 2 \\
\hline Phalanges 1 & 16 \\
\hline Phalanges 2 & 7 \\
\hline Phalanges 3 & 6 \\
\hline Sésamoïdes & 9 \\
\hline Côtes & 3 \\
\hline Vertèbres & 7 \\
\hline Métapodes & 17 \\
\hline Total & $\mathbf{1 1 2}$ \\
\hline
\end{tabular}

Tabl. 3 - Inventaire anatomique des restes de pore de la structure 70) ren nombre de restes). difficiles à évaluer, de possibilités de restitutions articulaires d'éléments de bas de pattes. Ces remontages signalent un lot d'ossements faiblement dispersés, provenant d'un nombre réduit d'individus, représentés par des parties de squelettes plus ou moins complètes. En toute logique il ne peut s'agir que de restes assez rapidement enfouis et qui du fait de ces conditions de formation particulières composent, contrairement à ceux plus épars des autres structures, un échantillon marqué par une grande cohésion interne. L'organisation spatiale de ces restes entre différentes zones de concentrations que relient de nombreux cas de recollages implique la simultanéité de leur dépôt. À cette caractéristique s'ajoute le fait que l'intégralité des ossements associés à cette structure ont pu être déterminés alors que dans tous les autres ensembles, près de la moitié des fragments n'ont pu être attribués à une espèce précise. Ce succès des déterminations est, dans le cas de la fosse 70 , directement lié aux nombreuses possibilités de recollages de restes de mandibules ou d'os longs qui permettent la reconstitution d'os entiers, dont la détermination est plus aisée que des pièces fragmentaires, ainsi qu'à la prépondérance de parties de squelettes. Ces caractéristiques attirent l'attention sur la nature singulière du lot de faune issu de cette structure et sur les conditions particulières qui ont présidé à sa constitution.

Dans les lots de faune attribués au groupe d'Entzheim. les restes de porcs sont très largement prépondérants. Cette caractéristique est surtout due à la composition particulière de la fosse 70 qui, à l'exception de 3 côtes de bœuf, ne contenait que des restes de porcs. L'importance de cet animal transparaît autant à travers le nombre de restes que leur masse, ce qui confère une certaine cohérence à ces données même si elles ne peuvent être considérées comme représentatives du rôle économique dévolu à cet animal. Cette appréciation est confortée par les particularités qui se décèlent au niveau du choix des animaux en fonction de l’âge. Parmi les restes dégagés dans cette structure peuvent être individualisés 4 sujets qui sont tous des femelles dont les âges, d'après l'usure dentaire 
(Horard-Herbin, 1997), s'échelonnent entre 1 an $1 / 2$ pour l'animal le plus jeune et 5-7 ans pour le plus vieux. Il s'agit d'animaux en âge d'assurer la reproduction et leur représentation dans cette fosse ne peut être le fait du hasard, car généralement les porcs sont abattus à un âge beaucoup moins avancé. Cette sélection contribue au caractère particulier de l'assemblage qu'enregistre par ailleurs aussi la distribution anatomique marquée par un net déséquilibre en faveur des mandibules et des bas de pattes. L'absence de traces de découpe au niveau des mandibules et la présence d'éléments de très faible calibre et très labiles, comme les sésamoïdes, laissent penser au dépôt de pièces non dépouillées qui pourraient correspondre à des rejets d'une phase peu avancée du traitement des carcasses, la préparation proprement dite, au cours de laquelle sont évacuées les parties peu intéressantes et encombrantes. Cette composante n'est cependant pas la seule représentée car des restes des os des membres (épaule et cuisse) qui, contrairement aux précédents, présentent de fréquentes marques de découpe procédant du prélèvement de la viande, sont également attestés.

En dépit de leur faible importance numérique, ces lots de faune ont aussi livré quelques pièces complètes, non fragmentées ou reconstituées par recollage, qui permettent d'accéder à des caractéristiques comme les longueurs, rarement accessibles en raison de l'intensité de la fragmentation et à partir desquelles peut être évaluée la hauteur au garrot des animaux. Deux os longs de porc, un radius en st. 8 et un humérus en st. 70 permettent ainsi de proposer deux estimations de la taille au garrot (coefficients de Teichert, 1969) qui varient entre 72,3 et $76,7 \mathrm{~cm}$, soit des valeurs proches de celles enregistrées sur d'autres sites de la région (Arbogast, 1994).

\section{Bilan de l'occupation du groupe d'Enthzeim}

L'ensemble clos de vases entiers du dépôt de la structure 58 est le fait le plus marquant de l'occupation du Néolithique moyen/récent. Malheureusement. la mauvaise conservation du site ne permet pas de replacer cet assemblage dans un contexte spatial. De plus. l'unicité du dépôt dans l'horizon culturel Entzheim/Michelsberg interdit toute interprétation hâtive. Le principal intérêt du dépôt est représenté par sa valeur chronologique certaine, puisqu'il s`agit d'un ensemble clos. La prédominance de la composante Michelsberg indique le caractère tardif de l’assemblage. La perte de caractères épi-Rössen peut parallèlement être envisagée d'après l'absence de pastilles à la jonction du col et de la panse sur la bouteille décorée typique du groupe d'Entzheim.

Par ailleurs, l'organisation des vases entiers ainsi que leur association à un amas de vases brisés et à deux pendeloques sont porteurs d'une signification symbolique. La diversité des récipients et leur grande taille en particulier marquent l'originalité du dépôt.

Enfin, les diverses influences culturelles à l'origine de la définition du groupe d'Entzheim se manifestent non seulement dans certains éléments de la céramique mais aussi dans d'autres de l'industrie osseuse. L'influence du groupe de Wauwil est attestée dans un décor à la tige creuse. L'influence chasséenne l'est également de façon plus hypothétique dans la grande coupe à anses tubulaires. De surcroît, l'outil en os perforant de la structure 59 révèle un savoir-faire caractéristique du Chasséen/Cortaillod/Lagozza.

Remerciements : nous remercions Marina Lasserre pour son soutien dans l'élaboration de ce travail et Christian Jeunesse pour ses conseils et son aide bibliographique.

Annexe 1 :

Biométrie des restes osseux datés du Rubané (code de mesures selon von den Driesch, 1976).

\begin{tabular}{|l|c|c|c|}
\hline \multicolumn{4}{|l|}{ BOVINS } \\
\hline Radius & Bp & Bfp & Dp \\
\hline St. 89 & 83,6 & 77,3 & 43,1 \\
\hline
\end{tabular}

\begin{tabular}{|l|c|c|c|c|c|c|}
\hline \multicolumn{1}{|l|}{ PORC } \\
\hline Radius & GL & Bp & Dp & SD & Bd & Dd \\
\hline St. 8 & 137,5 & 27,9 & 19 & 18,2 & 31,1 & 17,8 \\
\hline
\end{tabular}

\begin{tabular}{|l|c|c|}
\hline \multicolumn{3}{|l|}{ CHEVREUIL } \\
\hline Radius & Bd & Dd \\
\hline St. 8 & 26,1 & 17,8 \\
\hline
\end{tabular}

\begin{tabular}{|c|c|c|c|}
\hline \multicolumn{3}{|c|}{ CAPRINÉS } & \\
\hline \begin{tabular}{l|l} 
Humérus & $\mathrm{Bp}$
\end{tabular} & $\mathrm{Bp}$ & Dp & \\
\hline St. 106 & 46,2 & 37 & \\
\hline Radius & $B p$ & Dp & \\
\hline St. 8 & 28,6 & 15,3 & chèvre \\
\hline St. 98 & 29,1 & 15,5 & chèvre \\
\hline Calcaneun & $m$ & & \\
\hline St. 8 & & 8 & \\
\hline Tibia & Bd & Dd & \\
\hline St. 8 & 29 & 20,4 & \\
\hline Fémur & $\mathrm{Bp}$ & Dp & \\
\hline St. 8 & 41,5 & 19,2 & mouton \\
\hline
\end{tabular}


Annexe 2:

Biométrie des restes osseux datés du groupe d’Entzheim

(code de mesures selon von den Driesch. 1976).

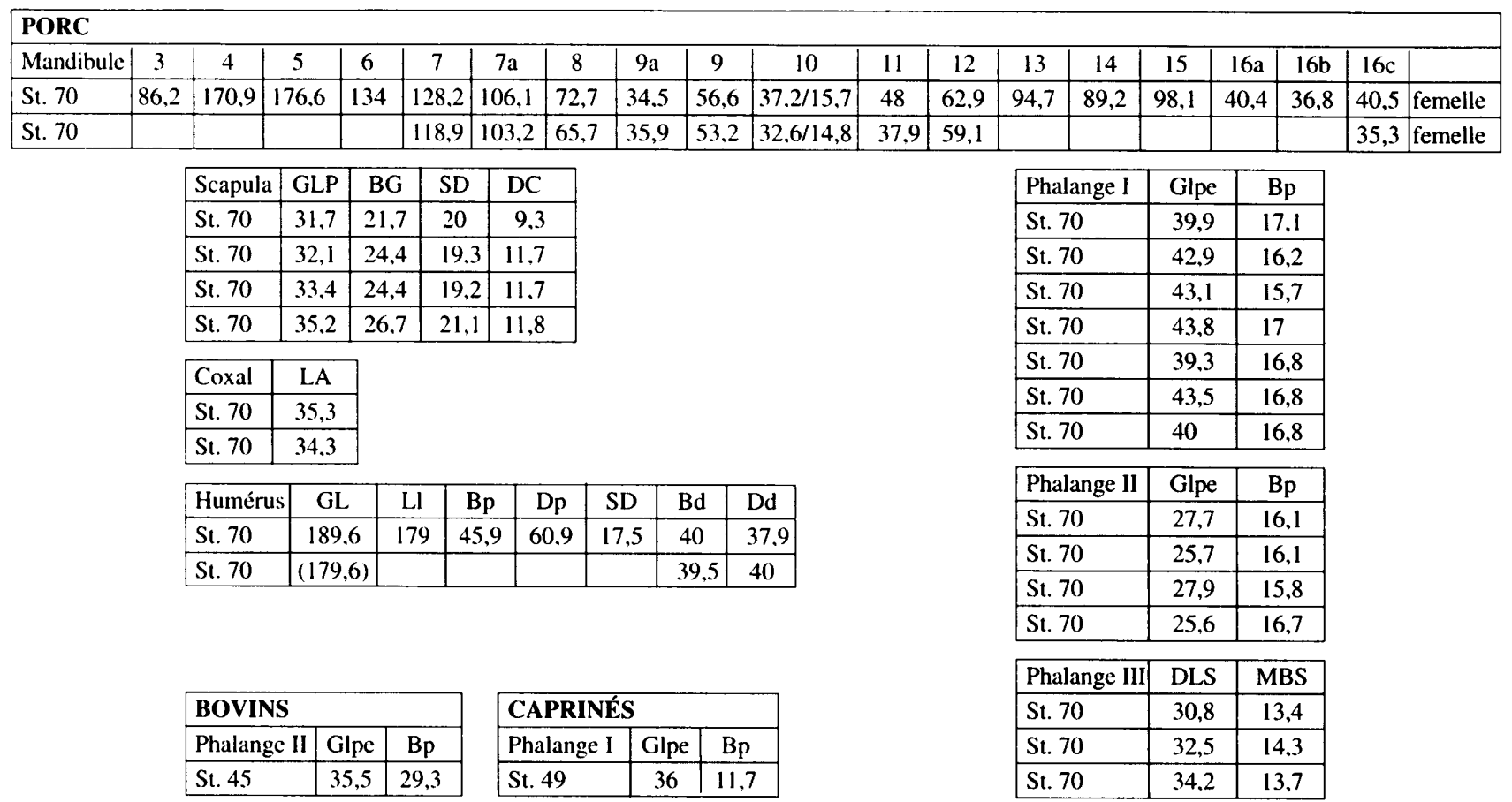

\section{RÉFÉRENCES BIBLIOGRAPHIQUES}

ARBOGAST R.-M. (1994) - Premiers élerages néolithiquess du NordEvi de la France'. ERAUL n 67 . Liège. 165 p.

ARBOGAST R.-M. (1998) - Contribution de l'archéozoologic du site Michelsberg de Mairy (Ardennes) à l'étude de l'origine de la variabilité des faunes du Néolithique récent du Nord de la France, Die Michelherger Kultur und ihre Randgebiete - Probleme der Enstehung. Chronologie und des Siedlungswese'ns. Kolloquium He'mmenhofen. 2/-2.3.2. 1997 . Materialhefte zur Archäologie in Baden-Württemberg. 43. Stuttgart, p. 135-142.

BEECHING A. (1991) - Sépultures, territoire et sociétés dans le Chasséen méridional. L 'exemple du Bassin rhodanien. Identité du Chasséen. Acte's du colloque international de Nemours. 1989. p. 327-342.

CLOTTES J.. GIRAUD J.-P. (1991) - Le Chasséen des Grands Causses et du Quercy. Ide'ntité du Chassée'n. Actes du collocule international de Nemours, 1989, p. 19-26.

COLAS C. (2000) - Sanoir-faire techmique at reconstimuton des chaines opératoiress des potiers att Nélithique mosen II dams la moitié nord de la France' : étude te' hnotypologique'. thèse de doctorat, université de Paris I. 3 vol

DIECKMANN B. (1990) - Dic Kulturgruppen Wauwil und Strassburg im Kaiserstuhlgebiet. Cahiers de I Association pout la Promotion de la Recherche archéologique' en Alsace, 8, p. 7-60.

DOHRN-IHMIG M. (1974) - Untersuchungen zur Bandkeramik im Rheinland, Rheinisc he Ausgrabunge'n. 15, p. 51-142.

DRIESCH A. von den (1976) - A Guide to the Measurement of Animal Bones from Archaeological Sites. Peabody Museum Bulletin I. Peabody Museum of Archaeology and Ethnology, Harvard University. $1.36 \mathrm{p}$.

DUBOULOZ J.. HAMARD D., LEBOLL.OCH M. (1997) - Composantes fonctionnelles et symboliques d'un site exceptionnel Bazoches-sur-Vesle (Aisne). 4000 ans av. J.-C.. in G. Auxiette. L.
Hachem et B. Robert dir. Espaces physiques, espaces sociaux dans l'analyse interne des site's du Néolithiqué à l'Âge du Fer, $119^{\circ}$ congrè̀s CTHS, Amiens, 1994. p. 127-144

EHRETSMANN M. ( 1993)-Ensisheim Ratfeld (Haut-Rhin). L'habitat rubané. L'outillage osseux, in Dossier spécial : Recherches ét documents sur le Néolithicue' ancien du sud de la plaine du Rhin supérieur (.5400-4800 a. J.-C.). Cahiers de l'Association pour la promotion de la recherche archéologique en Alsace, 9, p. 89-107.

FLOTTÉ P.. NILLES R., GIRARD P. (2000) - Pfulgriesheim " Lotissement communal " (Bas-Rhin). DFS d'évaluation. SRA Alsace.

HENOCQ-POCHINOT C.. MORDANT D. (1991) - La marge sud-est du Bassin parisien : Chasséen et Néolithique moyen. Identité du Chasse'en. Actes du colloque international de Nemours, 1989, p. 199-210.

HORARD-HERBIN M.-P. (1997) - L'éle'vage et lés productions animalés dans l'économie de la fin du se'cond Âge du Fer. Le'vroux 4. Revue archéologique du Centre de la France. 12" supplément.

JEUNESSE C. (1982) - La culture de Michelsherg en Alsace : essai de șinthèse. mémoire de maîtrise, université des Sciences Humaines de Strasbourg.

JEUNESSE C. (1989) - La culture de Munzingen dans le cadre du "Jungneolithikum" du Sud-Ouest de l'Europe centrale d’après les découvertes récentes des sites alsaciens de Didenheim (Haut-Rhin) et Geispolsheim (Bas-Rhin). Cahiers de l'Association pour la Promotion de la Recherche archéologique en Alsace. 5. p. $155-184$.

JEUNESSE C. (1992) - Il y a 7000 ans I Alsace. Le site archéologique du lotissement de "Sainte-Odile" à Rosheim et les premiers agriculteurs de la Plaine d'Alsace, Catalogue d'exposition. APRAA.

JEUNESSE C. (1997) - Pratiques funéraires au Néolithique ancien. Sépultures et nécropoles danubiennes, $5500-4900$ a: J.-C.. Paris. Errance. $168 \mathrm{p}$. 
JEUNESSE C., LEFRANC P. (1999) - Rosheim "Saint-Odile" (BasRhin), un habitat rubané avec fossé d'enceinte - Première partie : les structures et la céramique, Cahiers de l'Association pour la Promotion de la Recherche archéologique en Alsace, 15, p. 5-112.

KOENIG M.-P. (1988) - Un site de la transition Néolithique moyenrécent découvert à Geispolsheim (Bas-Rhin), Cahiers de l'Association pour la Promotion de la Recherche archéologique en Alsace. 4 , p. 39-48.

KRAUSE R., ARBOGAST R.-M., HÖNSCHEIDT S., LIENEMANN J. PAPADOPOULOS S RÖSCH M. SIDÉRA I. SMETTAN HW. STRIEN H.C., WELGE K. (2000) - Die bandkeramischen Siedlungsgrabungen bei Vaihingen an der Enz, Kreis Ludwigsburg (Baden-Würtemberg), Bericht der Römisch-Germanischen Kommission, 79, 1998, p. 7-105.

LAURELUT C. (1989) - Le village Michelsberg des Hautes Chanvières à Mairy (Ardennes). Étude de la céramique, Gallia Préhistoire, 31. p. 127-137.

LASSERRE M.. LEBOLLOCH M. (1982) - Un ensemble clos Michelsberg à Cuiry-lès-Chaudardes, Rev'ue archéologique de Picardie, 4, p. 66-69.

LEFRANC P. ARBOGAST R -M . MAUVILLYM. VAN WILLIGEN S. (1998) - L'habitat Rubané final de Westhouse "Ziegelhof" (BasRhin), Cahiers de l'Association pour la Promotion de la Recherche archéologique en Alsace. 14, p. 5-43.

LEFRANC P.. DENAIRE A.. PELLISSIER J. (2001) - Bischoffsheim "Rue du Stade". Un site d'habitat du groupe d'Ent heim. rapport de fouille. SRA Alsace.

LÜNING J. (1968) - Die Michelsberg Kultur. Ihre Funde in Zeitlicher und räumlicher Gliederung. Bericht des Römisch-Germanische'n Kommission, 48, 1967. p. 1-350.

MAROLLE C (1989) - Le village Michelsberg des Hautes Chanvières à Mairy (Ardennes). Étude préliminaire des principales structures. Gallia Préhistoire, 31. p. 93-158.

MEUNIER K. (2002) - Pfulgriesheim (Bas-Rhin) : un dépôt de vases du groupe d'Entzheim. Bulletin de la Société préhistorique française'. t. 99.2 , p. $373-374$

MEUNIER K.. BALZER I.. TESNIER-HERMETEY C. (2001) Pfulgriesheim "Lotissement communal". Occupations néolithiques et protohistoriques. DFS de sauvetage urgent. SRA Alsace.

REITER S. (1998) - Die Keramik von Bruchsal Auc, Die Michelsherger Kultur und ihre Randgebiete' - Probleme der Enstehung. Chronologie und des Siedlumgswesens, Kolloquium Hemmenhofen. 21-23.2.1997. Materialhefie zur Archäologie in Baden-Wïrttemberg. 43. Stuttgart. p. $121-126$.

SAINTY J.. THÉVENIN A. (1977) - Contribution à l’étude du groupe néolithique d'Entzheim dans le Bas-Rhin, Re've' archéologique de I.Est et du Centre-Est, tome XXVIII, fasc. 3 et 4. p. 229-233.

SCHMITT G. (1974) - La transition entre le Néolithique moyen et le Néolithique final en Basse-Alsace. Rev'ue' archéologique de l'Est et du Centre-Est, t. XXV, 3-4, p. 277-364.

SCHMITT G. (1987) - Trouvailles inédites du Néolithique récent et final. Cahiers alsaciens d'Archéologie, d'Art et d'Histoire, 30. p. $35-73$.
SIDÉRA I. (1989) - Un complément des données sur les sociétés rubanées, l'industrie osseuse de Cuiry-lès-Chaudardes. British Archaeological Reports, International Series 520, Oxford, 163 p.

SIDÉRA I. (2000a) - Animaux domestiques, bêtes sauvages et objets en matières animales du Rubané au Michelsberg. De l'économie aux symboles, des techniques à la culture, Gallia Préhistoire, 42, p. 108-194.

SIDÉRA I. (2000b) - Les matières dures animales. L'outillage en os et en ivoire, in D. Ramseyer dir., Muntelier/Fischergässli. Un habitat néolithique au bord du lac de Morat (3895 à 3820 av'ant J.-C.). Cahiers d'Archéologie fribourgeoise. 15. Fribourg (Suisse), éd. Universitaires, p. 118-156.

SIDÉRA I (2000c) - Analyse des techniques et des fonctions matérielles et funéraires des objets en matières osseuses des sépultures collectives de Val-de-Reuil et Portejoic, in C. Billard dir., Rapport d'étude pour le PCR. Un système de sépultures collectives au Néolithique final à Val-de-Reuil et Portejoie (Eure). SRA Haute-Normandic. Paris. 20 p.

SIDÉRA I. (à paraître a) - Outils, armes et parures en os funéraires à la fin du Néolithique d après Val-de-Reuil et Portejoic (Eure) : représentations individuelles et pratiques collectives, Gallia Préhistorire.

SIDÉRA I (à paraître b) - Outils en os, en bois de cerf et sur dents du Néolithique. Identité de l'industrie de l'os Montbolo, in F. Claustre dir., La grotte de Montou. Corbères-les-Cabanes (Pyrénées orientales). Documents d'Archéologie française. Paris.

STAHL R. (1978) - Une fosse du groupe d'Entzheim dans la Kroettengass à Rosheim. Anmuaire de la Société d'Histoire e't d'Archéologie de Molsheim e'l e'miroms, p. 5-12.

TEICHERT M. (1969) - Osteometrische Untersuchungen zur Berechnung der Widerristhöhe bei vor- und frühgeschichtlichen Schweinen, Kïhm-Archir, 83. p. 237-292.

VAQUER J. (1991) - Aspects du Chasséen en Languedoc occidental. Habitat et culture matérielle, Identité du Chassée'n. Acte's du colloqué international de Nemours, 1989, p. 27-38

WERNERT P. (196.3) - Informations archéologiques. Gallia Préhistoire. 6. p. 182-191

Katia MEUNIER

Doctorante à l'Université de Paris I, INRAP UMR 7041 ArScAn, Protohistoire européenne

Maison René-Ginouvès

21, allée de l'Université, 92023 Nanterre Cedex kmeunier@mae.u-paris10.fr

Isabelle SIDÉRA

UMR 7055 ArScAn. Préhistoire et technologie Maison René-Ginouvès 21, allée de l'Université, 92023 Nanterre Cedex sidera@mae.u-paris10.fr

Rose-Marie ARBOGAST

CNRS - Universität Basel 9-11 Petersgraben, $\mathrm{CH}$ - 4051 Basel 